\title{
TITANITA-BIOTITAGRANITOS DO BAIXO RIO UAUPÉS, PROVÍNCIA RIO NEGRO, AMAZONAS. PARTE II: GEOQUÍMICA E PETROGÊNESE
}

\author{
ROBERTO DALL'AGNOL*
}

\begin{abstract}
TITANITE-BIOTITE GRANITES OF THE UAUPÉS RIVER, RIO NEGRO PROVINCE, AMAZONAS STATE, BRAZIL. PART II: GEOCHEMISTRY AND PETROGENESIS. The Rio Uaupés Granite (RUG) is subalkalic, meta-aluminous cafemic, relatively rich in $\mathrm{CaO}, \mathrm{K} 2 \mathrm{O}, \mathrm{Rb}, \mathrm{Zr}, \mathrm{Nb}$ and $\mathrm{Y}$, with very high $\mathrm{FeO}$, $\left(\mathrm{FeO}_{\mathrm{t}}+\mathrm{MgO}\right)$ and $\mathrm{K}_{2} \mathrm{O} / \mathrm{Na}_{2} \mathrm{O}$ ratios, and fall in the fieldof within plate granites of the $\mathrm{NbxY}$ and $\mathrm{Rbx}(\mathrm{YNb})$ plots. Their REE signatures suggest only moderate fractionation ofplagioclase in the primitive magma or source material, while the fractionation ofhornblende, possibly associated with that of clinopyroxene and garnet, should be more intense. The RUG has no affinities neither with the calc-alkal ine granitoids found in island-arcs and Andean type continental margins, nor with granitoids of Phanerozoic collisional zones. It is also distinct from the shoshonitic granitoids, as well as the most common rapakivi granitoids. There are, however, strong similarities between the RUG and the Proterozoic, A-type granitoids of the southwestern United States. The crystallization of the TBMG should begin at temperatures near $950 " \mathrm{C}$ and finish about $700 " \mathrm{C}$, at pressures estimated between $8.5 \pm 1.5 \mathrm{kbarand} 4.5 \pm 0.5 \mathrm{kbar}$. The liquid was poor in volatile phases. The RUG magma evolved under relatively high oxygen fugacity (near the NNO and HIMTQ buffers). Concerning the evolution of the RioNegro Province, acontinental collision (A type)or, less probably, development of a mobile belt, both with important magmatism associated, are the suggested models. The RUG magma would be formed by the high temperature partial anatexis of a thickened lower crust, composed probably of quartz diorites and diorites orquartzgabbrosjotunitesandmangerites.
\end{abstract}

Keywords: Granitogenesis, RioNegro Province, Amazônia, Middle Proterozoic, magnetite series granites, A-type granites.

RESUMO OGranitoRioUaupés(GRU)ésubaIcalino,metaluminosocafêmico,relativamentericoemCaO, $\mathrm{K}_{2} \mathrm{O}$, $\mathrm{Rb}, \mathrm{Zr}, \mathrm{Nb}$ e $\mathrm{Y}$, e possui razões $\mathrm{FeO}_{\mathrm{t}} /\left(\mathrm{FeO}_{\mathrm{t}}+\mathrm{MgO}\right)$ e $\mathrm{K}^{\wedge} \mathrm{O} / \mathrm{NaiO}$ muito elevadas. Situa-se no campo dos granitos intraplacas em diagramas $\mathrm{NbxY}$ e $\mathrm{Rbx}(\mathrm{Y}+\mathrm{Nb})$. Suas assinaturas de terras raras indicam um fracionamento de plagioclásio no magma primitivo ou no resíduo de anatexia apenas moderado, ao passo que a separação de hornblenda e, talvez clinopiroxèfiio e granada, deve ter sido mais importante em volume. O GRU não tem afinidades nem com granitóides cálcio-alcalinos, típicos de arcos-de-ilhas e margens continentais do tipo andino, nem com aqueles identificados em zonas colisionais fanerozóicas. É igualmente distinto dos granitóides shoshoníticos e rapakivíticos mais comuns. São constatadas, no entanto, fortes similaridades entre o GRU e os granitóides proterozóicos do tipo A, encontrados no sudoeste dos Estados Unidos. As estimativas para cristalização do TBMG são temperaturas de $950^{\circ} \mathrm{C}$ a $700^{\circ} \mathrm{C}$ e pressões de $8,5 \pm 1,5 \mathrm{a} 4,5 \pm 0,5 \mathrm{kbar}$, respectivamente para o início e o fim da cristalização, sendo o líquido pobre em fases voláteis. $\mathrm{O}$ magmaevoluiu em condições de fugacidade de oxigênio elevada, similares às dos tampões NNO e HITMQ. Sobre a evolução da Província RioNegro, a hipótese de um arco magmático relacionado à subducção de crosta oceânica não é conciliável com asuagranitogênese. Em razão disso, neste trabalhoéassumidaahipótese de colisão continental (tipo A) ou, menos provavelmente, de geração de um cinturão móvel, ambos com intenso magmatismo associado, para explicar a sua evolução. O magma gerador do GRU seria formado por anatexia de alta temperatura de uma crosta inferior, espessada tectonicamente, composta provavelmente por quartzo-dioritos e dioritos ou quartzo-gabros, jotunitos e mangeritos.

Palavras-chaves: Granitogênese, Província Rio Negro, Amazônia, Proterozóico Médio, granitos com magnetita, granitos tipo-A.

INTRODUÇÃO Na primeira parte desse estudo (Dali Agnol \& Macambira 1992) foram discutidas a petrografia, suscetibilidade magnética e geocronologia do Granito Rio Uaupés (GRU). Nessa segunda, será efetuada a caracterização geoquímica e petrológica do GRU e estabelecidas comparações entre o mesmo e granitóides representativos de diferentes ambientes tectônicos. Com isso, este trabalho pretende contribuir para o conhecimento dos titanita-biotita granitos do tipo Uaupés, que são volumetricamente expressivos na Província Rio Negro (PRN), e para a reavaliação do ambiente tectônico dessa província. Procura, também, comparar o GRU com outros tipos de granitóides conhecidos no Cráton Amazônico.

METODOLOGIA A maioria das análises químicas foi efetuada nos laboratórios do Centro de Geociências da UFPA. $\mathrm{SiO}_{2}, \mathrm{TiO}_{2}, \mathrm{Al}_{2} \mathrm{O}_{3}, \mathrm{Fe}_{2} \mathrm{O}_{3 \text { total }}, \mathrm{CaO}, \mathrm{K}_{2} \mathrm{O}, \mathrm{P}_{2} \mathrm{O}_{5}, \mathrm{Rb}, \mathrm{Sr}, \mathrm{Zr}, \mathrm{Y}$ e $\mathrm{Nb}$ foram determinados através de fluorescência de raios $\mathrm{X}$; $\mathrm{Na}_{2} \mathrm{O}, \mathrm{MgO}$ e $\mathrm{MnO}$ tiveram seus teores obtidos por absorção atômica; $\mathrm{FeO}$ foi determinado por via úmida. Os elementos terras-raras foram analisados por espectrometria de plasma nos laboratórios da empresa GEOSOL.

GEOQUÍMICA Elementos maiores $\mathrm{Na}$ tabela 1, são apresentadas as análises químicas de 11 amostras representativas dos granitóides estudados, incluindo sete amostras de titanita-biotita monzogranitos (TBMG), uma amostra de biotita granodiorito (BGD), duas amostras de leucomonzogranitos (LMG) e uma amostra de leucossienogranito (LSG). Os TBMG tem composições muito homogêneas, sendo pequenas as variações nas proporções de $\mathrm{SiO}_{2}$ e dos demais óxidos. Quimicamente, o BGD (UA-20) não difere muito dos TBMG. No entanto, ele é algo mais aluminoso, apresenta teores de $\mathrm{Na}_{2} \mathrm{O}$ e $\mathrm{Sr}$ maiores e valores de $\mathrm{K}_{2} \mathrm{O} / \mathrm{Na}_{2} \mathrm{O}, \mathrm{Rb} / \mathrm{Sr}$ e $\mathrm{Ca} / \mathrm{Sr}$, menores quando confrontado aos TBMG. Nos TBMG e BGD, são destacáveis os teores expressivos dos constituintes ferromagnesianos, em particular, de $\mathrm{TiO}_{2}$ e $\mathrm{P}_{2} \mathrm{O}_{5}$, e as elevadas razões $\mathrm{FeO}_{\mathrm{t}} /\left(\mathrm{FeO}_{\mathrm{t}}+\mathrm{MgO}\right)$. As proporções de $\mathrm{CaO}$ também são 
Tabela 1 - Análises químicas em rocha total do Granito Rio Uaupés. Elementos maiores e menores (\% em peso) e traços (ppm). Análises do Departamento de Geoquímica-Petrologia (CG-UFPA)

Table 1 - Whole-rock chemical analyses of Rio Uaupés Granite

\begin{tabular}{|c|c|c|c|c|c|c|c|c|c|c|c|}
\hline \multirow{2}{*}{$\frac{\text { VARIEDADE }}{\text { AMOSTRASI }}$} & \multirow{2}{*}{\begin{tabular}{|c|}
$\begin{array}{c}\text { BIOT GRANOD } \\
\text { (BGD) }\end{array}$ \\
UA - EV \\
\end{tabular}} & \multicolumn{7}{|c|}{$\begin{array}{l}\text { TITANITA-BFTITA MONZOGRANITO } \\
\text { (TERAG) }\end{array}$} & \multicolumn{2}{|c|}{$\begin{array}{l}\text { LEUCOMONZOGR } \\
\text { (L,WG) }\end{array}$} & \multirow{3}{*}{\begin{tabular}{|c}
$\begin{array}{c}\text { LEUCO-SIENOG } \\
\text { (LSG) }\end{array}$ \\
UAEV \\
23
\end{tabular}} \\
\hline & & UA.EV & PT.33 & UAEV & UAEV & PT-33 & PT.33 & PT-33 & UAEV & UAEV & \\
\hline oxioos & 20 & 7 & B1 & a & 11 & $A 3$ & A. 5 & A1 & 13 & 14 & \\
\hline \$10: & 66,99 & 66.52 & 66.59 & 66,74 & 67.34 & 67.73 & 67,83 & 67.91 & 72.66 & 77,15 & 76,40 \\
\hline Two: & 0,72 & 0,81 & 0,92 & 0,85 & 0,80 & 0,84 & 0,78 & 0,76 & 0,27 & 0,10 & 0,26 \\
\hline A & 15.28 & 14,91 & 14.58 & 14.77 & 14.70 & 14.76 & 14.48 & 15,06 & 14,51 & 12.28 & 12,98 \\
\hline FeO & 1,79 & 2,3 & 2,38 & 2,14 & 2,19 & 2,33 & 2,09 & 2.12 & 0,63 & 0,51 & 0,59 \\
\hline$F_{\theta D}$ & 2,16 & 2,23 & 2.23 & 2,37 & 2.16 & 2,01 & 2.10 & 1,65 & 0.57 & 0.36 & 0.57 \\
\hline Mno & 0,14 & 0,08 & 0,10 & 0,08 & 0,10 & 0,10 & 0,10 & 0,07 & 0,05 & 0,05 & 0,03 \\
\hline$M g O$ & 0,82 & 0.83 & 0,25 & 0,25 & 0,90 & 0,69 & 0,78 & 0,72 & 0,25 & 0.20 & 0,20 \\
\hline $\mathrm{CaO}$ & 3.03 & 3.19 & 3,23 & 3,42 & 3,10 & 3,07 & 2,95 & 2,98 & 1.26 & 0,86 & 0,99 \\
\hline $\mathrm{N}=0$ & 3,3 & 2,8 & 2,7 & 2,6 & 3,3 & 3.1 & 2,8 & 2,7 & $2, \mathbf{a}$ & $2, \mathbf{f}$ & 1,8 \\
\hline 160 & 5,01 & 4,96 & 5,10 & 4,7 & 4,91 & 5.13 & 5,09 & 5.22 & 7.07 & 5,11 & 6,47 \\
\hline$P=0$ & 0.26 & 0.30 & 0,33 & 0,30 & 0,28 & 0,30 & 0,29 & 0,26 & 0,07 & 0,04 & 0,06 \\
\hline P.F. & 0.38 & 0.26 & 0.16 & 0.26 & 0.26 & 0.18 & 0,39 & 0.34 & 0,44 & 0,52 & 0,54 \\
\hline TOTAL & 99,85 & $9 \Leftrightarrow 19$ & 99.48 & 99,10 & 100,03 & 100.44 & 99,65 & 99,79 & 100,38 & 89.78 & 100,79 \\
\hline Rb & 235 & 225 & 250 & 227 & 226. & 248 & 261 & 237 & 395 & 229 & 206 \\
\hline $\mathrm{sr}$ & 303 & 261 & 276 & 287 & 276 & 260 & 258 & 277 & 240 & 66 & 323 \\
\hline 2 & 262 & 288 & 318 & 398 & 307 & 263 & 272 & 309 & 77 & 79 & 147 \\
\hline$Y$ & 71 & 70 & 69 & 61 & 73 & 79 & 62 & 96 & 210 & 30 & 7 \\
\hline Nh & 23 & 21 & 27 & 26 & 23 & 25 & 26 & 26 & 13 & 9 & 8 \\
\hline FrOAfo: & 1,21 & 0,97 & 0,94 & 1,11 & 0,99 & 0,86 & 1,01 & 0,78 & 0,30 & 0.71 & 0,97 \\
\hline KONaSO & 1,52 & $1, \pi$ & 1,89 & 1,69 & 1,49 & 1,65 & 1,81 & 1,93 & 2.72 & 1,97 & 3,59 \\
\hline $\mathrm{Rb} / \mathrm{Sr}$ & 0.78 & 0.86 & 0,97 & 0,78 & 0,62 & 0.95 & 1,01 & 0,86 & 1,35 & 3,47 & 0,64 \\
\hline Carsr & 71 & e7 & 83 & 85 & 80 & 84 & 81 & 78 & 30 & 93 & 22 \\
\hline KRb & 177 & 183 & 169 & 172 & 180 & 172 & 162 & 183 & 175 & 185 & 281 \\
\hline$R t w z r$ & 0,90 & 0,78 & 0,79 & 0,57 & 0,74 & 0,94 & 0,98 & $0 . \pi$ & 4,35 & 2,90 & 1,40 \\
\hline
\end{tabular}

altas para monzogranitos. Entre os álcalis, é constatada a ampla dominância de $\mathrm{K}_{2} \mathrm{O}$ sobre $\mathrm{Na}_{2} \mathrm{O}$, traduzida em altas razões $\mathrm{K}_{2} \mathrm{O} / \mathrm{Na}_{2} \mathrm{O}$. Em resumo, são rochas ricas em $\mathrm{K}_{2} \mathrm{O}$, $\mathrm{TiO}_{2}$, $\mathrm{FeO}_{\mathrm{t}}, \mathrm{P}_{2} \mathrm{O}_{5}$ e $\mathrm{CaO}$ e, relativamente, empobrecidas em $\mathrm{MgO}$ e $\mathrm{Na}_{2} \mathrm{O}$.

Os LMG são quimicamente heterogêneos. A amostra UA13 tem um teor de $\mathrm{SiO}_{2}$ normal para monzogranitos, ao lado de alto teor de $\mathrm{K}_{2} \mathrm{O}$ e baixo de $\mathrm{Na}_{2} \mathrm{O}$. A outra (UA-14) é extremamente enriquecida em $\mathrm{SiO}_{2}$ e empobrecida em $\mathrm{Fe}_{\text {total }}$, $\mathrm{TiO}_{2}$ e MgO. O LSG é bastante próximo em composição desta última amostra; as duas possuem altas razões $\mathrm{K}_{2} \mathrm{O} / \mathrm{Na}_{2} \mathrm{O}$.

$\mathrm{O}$ limitado intervalo de variação de $\mathrm{SiO}_{2}$ nos TBMG e as variações descontínuas nos teores de $\mathrm{SiO}_{2}$ entre essas e as demais variedades, não fornecem trends claros nos diagramas petrológicos mais usuais. Portanto, somente os mais representativos foram selecionados para serem discutidos neste trabalho. No diagrama $\mathrm{CaO}-\mathrm{Na}_{2} \mathrm{O}-\mathrm{K}_{2} \mathrm{O}$ (Fig. la), é possível perceber a importância do $\mathrm{CaO}$ nessas rochas e a clara dominância do $\mathrm{K}_{2} \mathrm{O}$ sobre $\mathrm{Na}_{2} \mathrm{O}$. Os altos teores de $\mathrm{TiO}_{2}$ (Tab. 1) também são um aspecto marcante na associação estudada. No diagrama $\mathrm{TiO}_{2}-\mathrm{FeO}-\mathrm{Fe}_{2} \mathrm{O}_{3}$ (Fig. 1 b), as amostras de TBMG e BGD tendem a se aproximar mais do vértice do $\mathrm{TiO}_{2}$ do que outros magnetita granitos da Amazônia. A concentração excepcional de titânio reflete-se nos TBMG na abundância de titanita.

$\mathrm{O}$ diagrama $\mathrm{Fe}_{2} \mathrm{O}_{3} \times \mathrm{FeO}$ (Fig.2) mostra que as razões $\mathrm{FeO} /$ $\mathrm{Fe}_{2} \mathrm{O}_{3}$ situam-se em torno da unidade para o conjunto de amostras analisadas, reforçando as evidências obtidas por Dall'Agnol et al (1988) que haviam observado comportamento semelhante em outros magnetita granitos da Amazô- nia. Eles assinalaram que os dados analíticos até então disponíveis revelavam altas razões $\mathrm{FeO} / \mathrm{Fe}_{2} \mathrm{O}_{3}$ para os TBMG, o que era discordante com seus elevados valores de SM. Os mesmos autores destacaram que, por causa disso, no diagrama $\mathrm{FeO} /$ $\mathrm{Fe}_{2} \mathrm{O}_{3}$ versus índice de diferenciação (ID) os TBMG incidiam no campo dos ilmenita granitos, o que era absolutamente contraditório com as medidas de SM. Os dados obtidos neste trabalho são, portanto, mais coerentes com o que se deveria esperar teoricamente, pois todas as amostras analisadas incidem no diagrama ID x FeO/ $/ \mathrm{Fe}_{2} \mathrm{O}_{3}$ no campo dos magnetita granitos. No diagrama AFM (Fig. 3), as amostras analisadas não acompanham o /renofcálcio-alcalino, o que é um reflexo das suas altas razões $\mathrm{FeO}_{\mathrm{t}} /\left(\mathrm{FeO}_{\mathrm{t}}+\mathrm{MgO}\right)$. Essa interpretação é melhor evidenciada no diagrama R 1 -R2 (Fig. 4), conforme La Roche et al. (1980). Os TBMG e BGD mostram comportamento distinto daquele das séries cálcio-alcalinas, alinhandose segundo o trend subalcalino. Situam-se, além disso, no campo dos granodioritos pelos seus elevados teores de $\mathrm{CaO}$. No diagrama $[\mathrm{Mg} /(\mathrm{Fe}+\mathrm{Mg})]$ x B (Debon \& Lê Fort 1988), é destacado o caráter acentuadamente rico em ferro do Granito Uaupés (Fig. 5a). No diagrama A x B (Debon \& Lê Fort 1988), os TBMG e BGD situam-se no domínio metaluminoso e no campo IV (associações com biotita + anfíbólio \pm piroxênio), ao passo que os LMG e LSG acusam caráter ligeiramente aluminoso (Fig. 5b). A disposição dos TBMG e BGD deve-se, em parte, à influência de titanita e apatita que, juntamente com o anfíbólio, contribuem para situar tais rochas no campo metaluminoso. Considerando a ampla dominância dos TBMG e BGD sobre as demais variedades, o Granito Rio Uaupés pode 


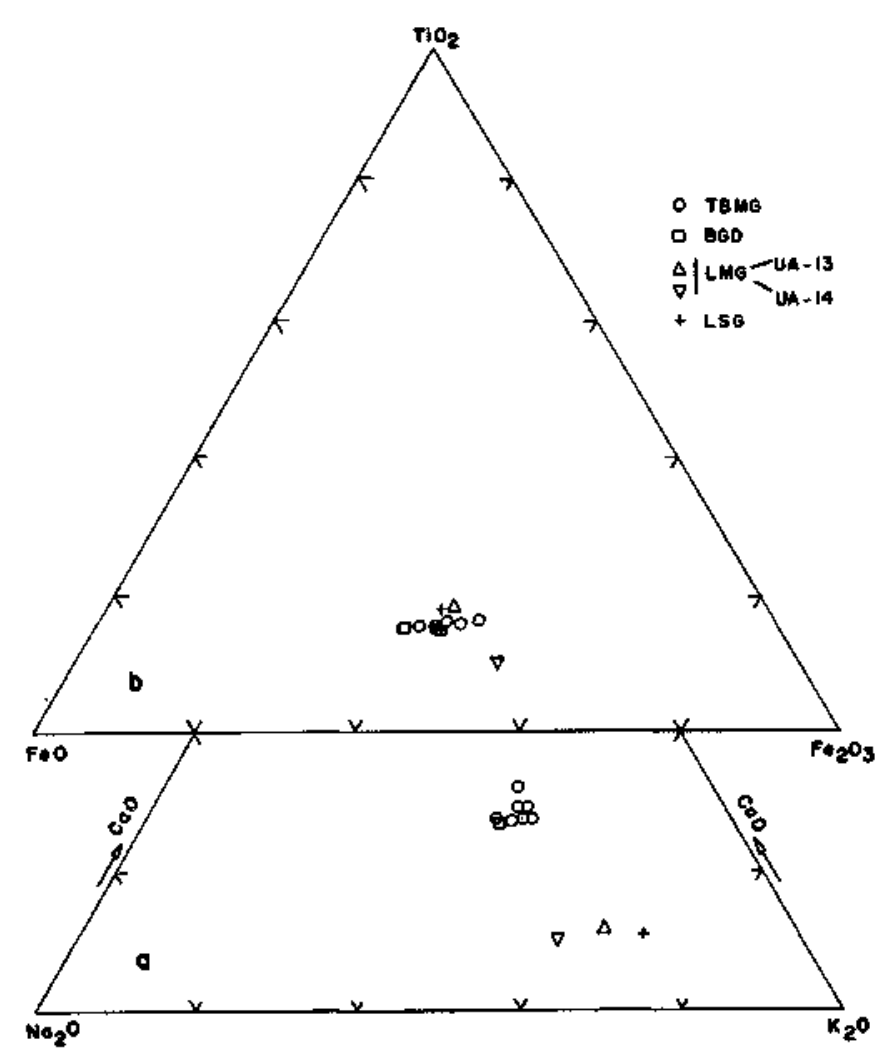

Figura Ia - Diagrama $\mathrm{CaO}-\mathrm{Na}_{2} \mathrm{O}-\mathrm{K}_{2} \mathrm{O}$ do Granito Rio Uaupés. Os símbolos adotados para as diversas fades são uniformes para as figuras 1 até 10. Titanita-biotita monzogranitos (TBMG) - círculos vazios; biotitagranodiorito (BGD)-quadradovazio; leucomonzogranitos (LMG) UA-13 - triângulo vazio, UA-23 triângulo vazio invertido; leucossienogranito (LSG) - cruz

Figure la-CaO- $\mathrm{Na}_{2} \mathrm{O}-\mathrm{K}_{2} \mathrm{Oplot}$ of the Rio Uaupés Granite. Titanite-biotite monzogranites (TBMG) - open circles; biotite granodiorite (BGD) - open square; leucomonzogranites (LMG): UA-13-open triangle, UA-23 - inversed open triangle; leucosyenogranite (LSG) - cross. These symbols hold for figures ItolO

Figura Ib- Diagrama $\mathrm{TiO}_{2} \mathrm{FeO}-\mathrm{Fe}_{2} \mathrm{O}_{3}$ do Granito Rio Uaupés Figure $1 \mathrm{~b}-\mathrm{T}_{2} \mathrm{O}_{3} \mathrm{FeO}-\mathrm{Fe}_{2} \mathrm{O}_{3}$ plot of the Rio Uaupés Granite

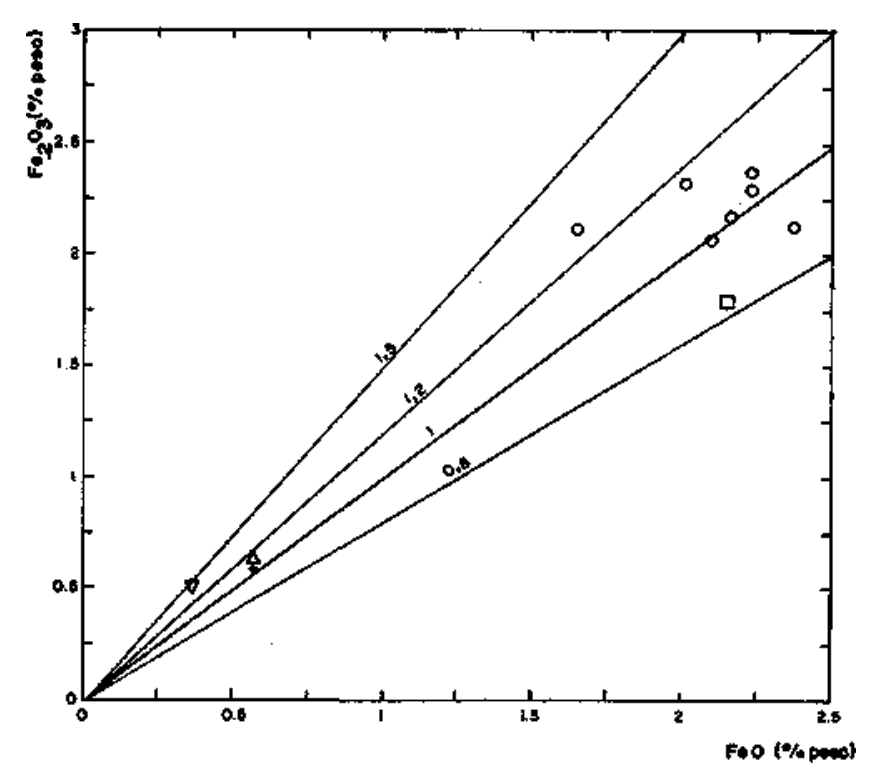

Figura 2 - Diagrama $\mathrm{Fe}_{2} \mathrm{O}_{3}-\mathrm{FeO}$ do Granito Rio Uaupés Figure $2-\mathrm{Fe}_{2} \mathrm{O}_{3}-\mathrm{FeO}$ plot of the Rio Uaupés Granite

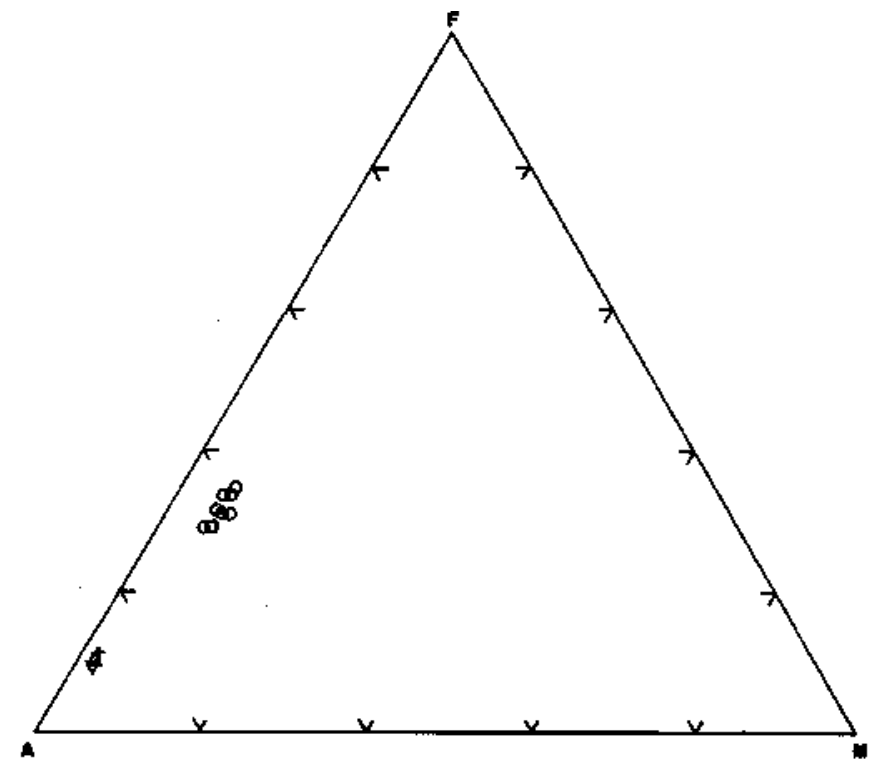

Figura 3 - Diagrama AFM do Granito Rio Uaupés Figure 3 - AFM plot of the Rio Uaupés Granite

ser considerado, de acordo com a classificação dos mencionados autores, como cafêmico. Concluindo, o Granito Rio Uaupés pode ser definido como subalcalino, cafêmico e rico em ferro.

As normas CIPW constam da tabela 2. São dignos de nota, nos TBMG e BGD, os teores moderados de quartzo normativo (21 a $26 \%)$, os teores relativamente altos de anortita (10,8 a $15 \%$ ), a dominância de ortoclásio sobre albita e a presença de dipsídio normativo $(0,23$ a $2,22 \%)$ e, em uma única amostra, de coríndon normativo $(0,2 \%)$. Nos LMG e LSG, aumentam as proporções de Qz, Or e coríndon e diminuem muito as de An. Essas características são coerentes com a composição modal e o diagrama A x B (Fig. 5b), confirmando serem os TBMG e BGD ligeiramente metaluminosos; as demais variedades são ligeiramente peraluminosas.

No diagrama Qz-Ab-Or (Fig. 6a), os TBMG situam-se na região correspondente à concentração máxima das rochas graníticas (Winkler 1979, Fig. 18-14); porém, mais próximos do vértice do Or do que a maioria delas. Sua distribuição é bastante coincidente com a posição da linha cotética ou

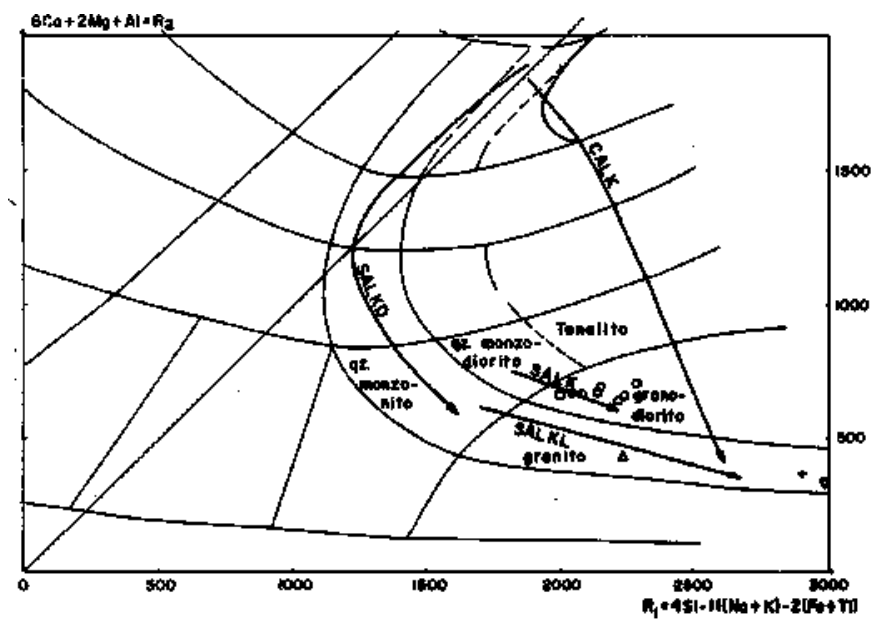

Figura 4- Diagrama R1R2 (La Roche et al. 1980), mostrando a distribuição das diversas fades do Granito Rio Uaupés

Figure4 -R1R2 plot (LaRoche e/a/. 1980) for rocks of the Rio Uaupés Granite 


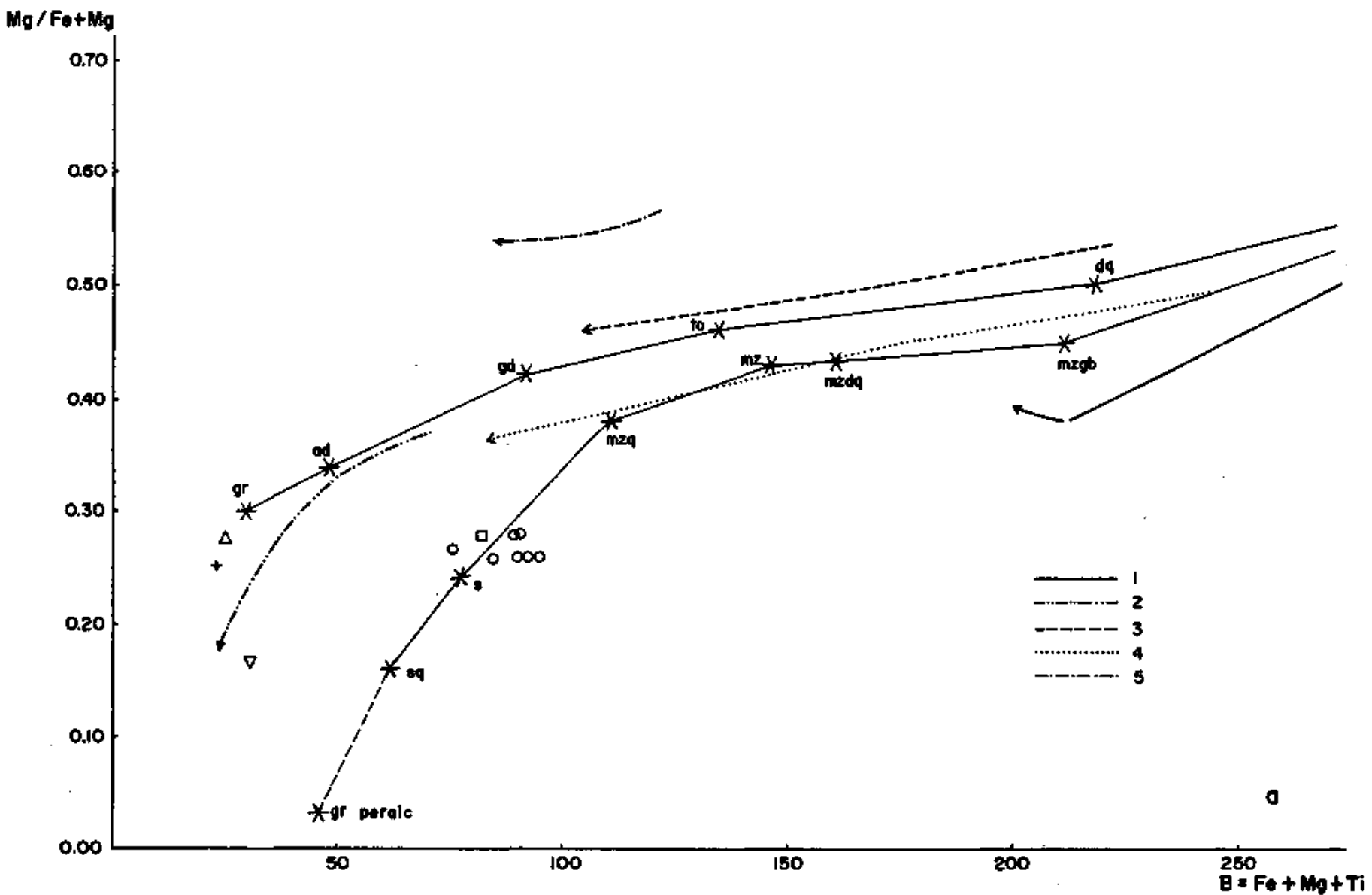

Figura 5 a - Diagrama $\mathrm{Mg}(\mathrm{Fe}+\mathrm{Mg})$ x B (Debon \& Lê Fort 1988), mostrando a distribuição do Granito Rio Uaupés em comparação com diversos exemplos extraídos da literatura: 1. Associação básica do Maciço de Ploumanac 'h; 2. Granitóides de Ploumanac 'h; 3. Fades máfica do Maciço de Ballons Sul; 4. Fades máfica do Maciço de Ballons Norte; 5. Monzogranitos de Ballons; (1 e 2 baseados em Barrière 1977; 3, 4 e 5 a partir de Pagel \& Leterrier 1980; curvas fornecidas ao autor por F. Debon). $d q$ - diorito com quartzo; to - tonalito; gd - granodiorito; ad - adamelito; gr - granito; mzgb - monzogabro; mzdq monzodiorito com quartzo; $m z$ - monzonito; mzq - monzonito com quartzo; $s$ - sienito; sq - quartzo-sienito; gr peralc - granito peralcalino (composições padrão baseadas em Debon et al. 1986)

Figure $5 \mathrm{a}-\mathrm{Mg} /(\mathrm{Mg}+\mathrm{Fe})$ x B plot (Debon \& Lê Fort 1988), showing the distribution of the Rio Uaupés Granite compared to several examples taken from the literature. Ploumanac'h complex: 1. basic rocks; 2. granitoids; Ballons complex: 3. mafic rocks from the southern area; 4 . maficrocks from the northern area; 5 . monzogranites (sources: 1,2. Barrière 1977; 3,4,5. Pagel \& Leterrier 1980; trends given to the authorby F. Debon). dq -quartz diorite; to-tonal ite; gd - granodiorite; ad- adamellite; gr-granite; mzgb-monzogabbro;mzdq -quartzmonzodiorite;mz-monzonite;mzq-quartzmonzonite;s-syenite;sq -quartzsyenite;grperalkalinegranite. (Standard compositions, Debon et al. 1986)

situam-se sobre as superfícies cotéticas, mas próximas da linha cotética (isotermas de 655 e $670^{\circ} \mathrm{C}$ ).

No diagrama An-Ab-Or (Fig. 6b), sobressaem as proporções elevadas de An nos TBMG, além da ligeira dominância do Or sobre Ab. Os LMG e LSG afastam-se do vértice da An e aproximam-se daquele do $\mathrm{Or}$, em razão de variações em $\mathrm{CaO}$ e $\mathrm{K}_{2} \mathrm{O} / \mathrm{Na}_{2} \mathrm{O}$. Todas as amostras analisadas plotam no campo dos granitps (Cf. Barker 1979). A distribuição dos pontos dos TBMG coincide ou situa-se muito próximo da projeção da linha cotética isobárica a $\mathrm{PH}_{2} \mathrm{O}=7 \mathrm{kbar}$ (Winkler 1979, Fig. 18-9).

Em relação aos demais granitos da Amazônia brasileira (Dall'Agnol et al. 1987, Figs. 8 a 13), o Granito Rio Uaupés particulariza-se por ser, ao mesmo tempo, rico em $\mathrm{CaO}$ e $\mathrm{K}_{2} \mathrm{O}$, fugindo à tendência geral de evolução geoquímica dos granitóides do Arqueano ao Proterozóico Médio, caracterizada pela correlação negativa entre $\mathrm{CaO}$ e $\mathrm{K}_{2} \mathrm{O}$ e pelas razões $\mathrm{K}_{2} \mathrm{O} / \mathrm{CaO}$ muito altas nos granitos ricos em $\mathrm{K}_{2} \mathrm{O}$. A influência das razões $\mathrm{K}_{2} \mathrm{O} / \mathrm{CaO}$ se traduz também em diferenças na distribuição do Granito Rio Uaupés em relação aos demais, nos diagramas $\mathrm{CaO}-\mathrm{Na}_{2} \mathrm{O}-\mathrm{K}_{2} \mathrm{O}$ e An-Ab-Or. Os TBMG são mais potássicos e menos sódicos do que costuma acontecer com granitóides com teores equivalentes de silica e relativamente cálcicos para granitóides tão ricos em potássio.

Elementos traços $\mathrm{Na}$ Tabela 1, também constam os resultados das análises de $\mathrm{Rb}, \mathrm{Sr}, \mathrm{Zr}, \mathrm{Y}$ e $\mathrm{Nb}$. Os teores de $\mathrm{Rb}$ e Sr nos TBMG são muito próximos, com a ligeira dominância do $\mathrm{Sr}$ refletindo-se em razões $\mathrm{Rb} / \mathrm{Sr}$, em geral, um pouco abaixo da unidade. Os teores de $\mathrm{Sr}$ são perfeitamente compatíveis com a composição desses granitos; os de $\mathrm{Rb}$, um pouco elevados para rochas com menos de $70 \%$ de $\mathrm{SiO}_{2}$, indicam que o magma original era enriquecido nesse elemento. Como ele acompanha geralmente o potássio, sua fixação na rocha foi favorecida pelos conteúdos modais importantes de feldspato alcalino (Fp) e biotita (Bt). Os teores de $\mathrm{Zr}$, Y e $\mathrm{Nb}$ são expressivos nessa variedade, refletindo certamente a fonte dos magmas e a abundância e diversidade dos minerais acessórios. O LMG UA-13 mostra-se enriquecido em Rb e com leve diminuição do $\mathrm{Sr}$, portanto, com razão $\mathrm{Rb} / \mathrm{Sr}$ mais alta. $\mathrm{Zr}$ e $\mathrm{Nb}$ decrescem muito nessa amostra, enquanto $\mathrm{Y}$ tem um valor muito alto, possivelmente devido à presença de allanita. No outro LMG (UA-14) e no LSG (UA-23), os teores de Zr, Nb 
Tabela 2 - Normas CIPW do Granito Rio Uaupés

Table 2 - CIPW norms of Rio Uaupés Granite

\begin{tabular}{|c|c|c|c|c|c|c|c|c|c|c|c|}
\hline VARIEDADE & $\begin{array}{c}\text { BIOT. GRANOD. } \\
\text { (BGD) }\end{array}$ & & TITA & VITA-BIO & $\begin{array}{l}\text { TITA MC } \\
\text { (TBMG) }\end{array}$ & NZOGRA & NITO & & $\begin{array}{r}\text { LEUCOA } \\
\text { (L }\end{array}$ & $\begin{array}{l}\text { SNZOGR } \\
\text { G) }\end{array}$ & $\begin{array}{c}\text { LEUCO-SIENO } \\
\text { (LSG) }\end{array}$ \\
\hline AMOSTRASI & $\mathrm{UA}-\overline{\mathrm{EV}}$ & UA-EV & PT-33 & $\overline{\text { UA-EV }}$ & UA-EV & PT-33 & PT-33 & PT-33 & UA-EV & UA-EV & UA-EV \\
\hline MINER. N. & 20 & 7 & B1 & 8 & 11 & A3 & A5 & A1 & 13 & 14 & 23 \\
\hline Quartzo & 21,3 & 23,9 & 24,0 & 25,6 & 22,3 & 23,1 & 25,3 & 25,3 & 27,5 & 40,7 & 38,7 \\
\hline Ortoclásio & 29,8 & 29,6 & 30,4 & 28,2 & 29,1 & 30,3 & 30,3 & 31,0 & 41,8 & 30,4 & 38,1 \\
\hline Albita & 28,1 & 24,0 & 23,0 & 22,3 & 28,0 & 26,2 & 23,9 & 23,0 & 22,0 & 22,2 & 15,2 \\
\hline Anortita & 12,2 & 13,6 & 13,5 & 14,9 & 10,8 & 11,2 & 12,0 & 13,2 & 5,8 & 4,0 & 4,5 \\
\hline Corindon & - & - & $=$ & $=$ & - & - & - & 0,2 & 0,5 & 1,0 & 1,3 \\
\hline Diopsidio & 1,0 & 0,3 & 0.4 & 0,2 & 2,2 & 1,6 & 0,7 & - & $\cdot$ & - & $\cdot$ \\
\hline "Hiperstenio" & 3,1 & 3,0 & 2.8 & 3.4 & 2,2 & 2.0 & 2,7 & 2,0 & 0.8 & 0,7 & 0.7 \\
\hline Magnetita & 2,6 & 3,4 & 3,5 & 3,1 & 3,2 & 3,4 & 3,0 & 3,1 & 0,9 & 0.7 & 0.9 \\
\hline Ilmenita & 1,4 & 1,6 & 1,8 & 1,6 & 1,5 & 1,6 & 1,5 & 1,5 & 0,5 & 0,2 & 0,5 \\
\hline Hematita & - & - & - & - & - & - & + & $=$ & $=$ & $=$ & - \\
\hline Apatila & 0,6 & 0,7 & 0,7 & 0.7 & 0,6 & 0,7 & 0,6 & 0,6 & 0,2 & 0,1 & 0.1 \\
\hline
\end{tabular}

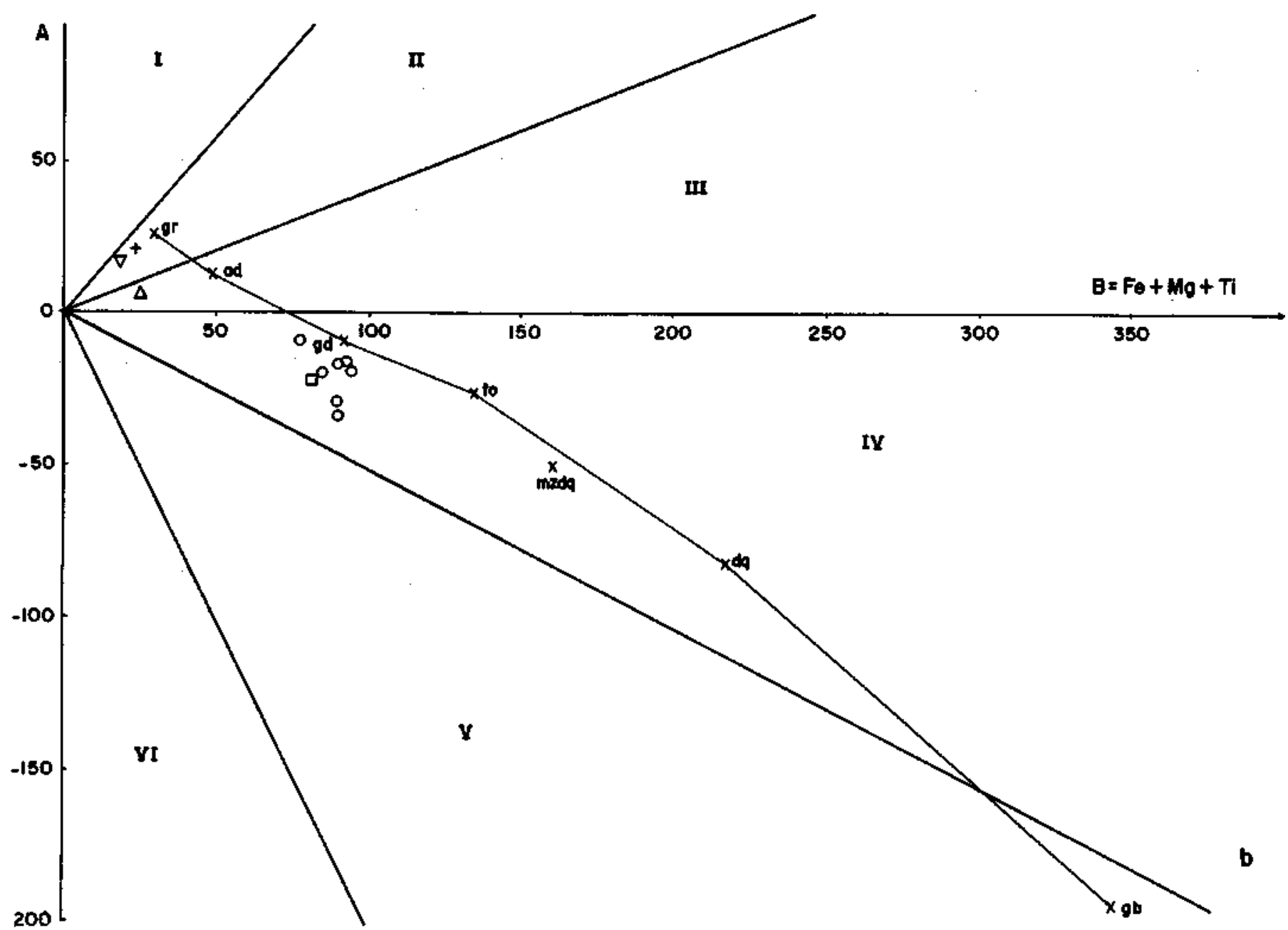

Figura $5 b$ - Diagrama AxB (Debon \& Lê Fort 1988), mostrando a incidencia dos titanita-biotita monzogranitos e biotita granodiorito do Rio Uaupés no campo IV; os leucomonzogranitos e leuco-sienogranito incidem nos campos III e II. gb - gabro; demais abreviações conforme figura 5 a (fonte: Debon et al. 1986)

Figure 5b - A x B plot (Debon \& Lê Fort 1988). Titanite-biotite monzogranites and biotite granodiorite plot in field IV whereas leucomonzogranites and leucosyenogranite plot in fields III and II; gb - gabbro; other abbreviations as in Figure 5a 


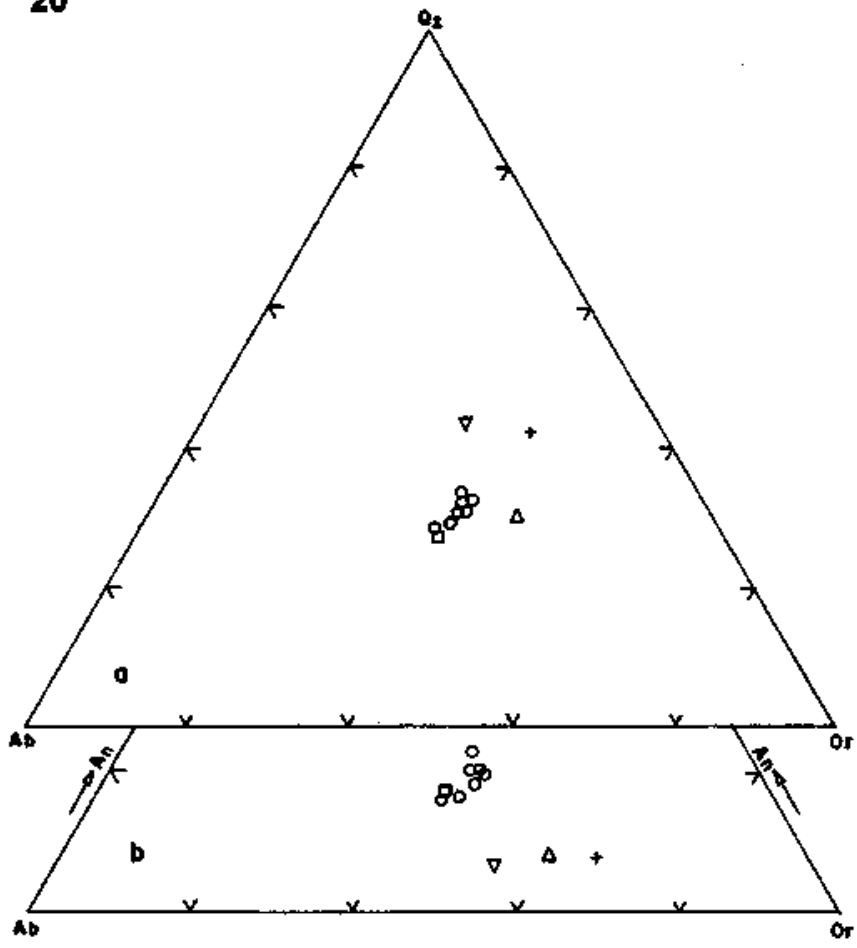

Figura $6 a$ - Diagrama normativo Qz-Ab-Or do Granito Rio Uaupés

Figure 6a - Normative Qz-Ab-Or plot of the Rio Uaupés Granite

Figura $6 b$ - Diagrama normativo An-Ab-Or do Granito Rio Uaupés

Figure $6 \mathrm{~b}$-Normative An-Ab-Or plot of the Rio Uaupés granite

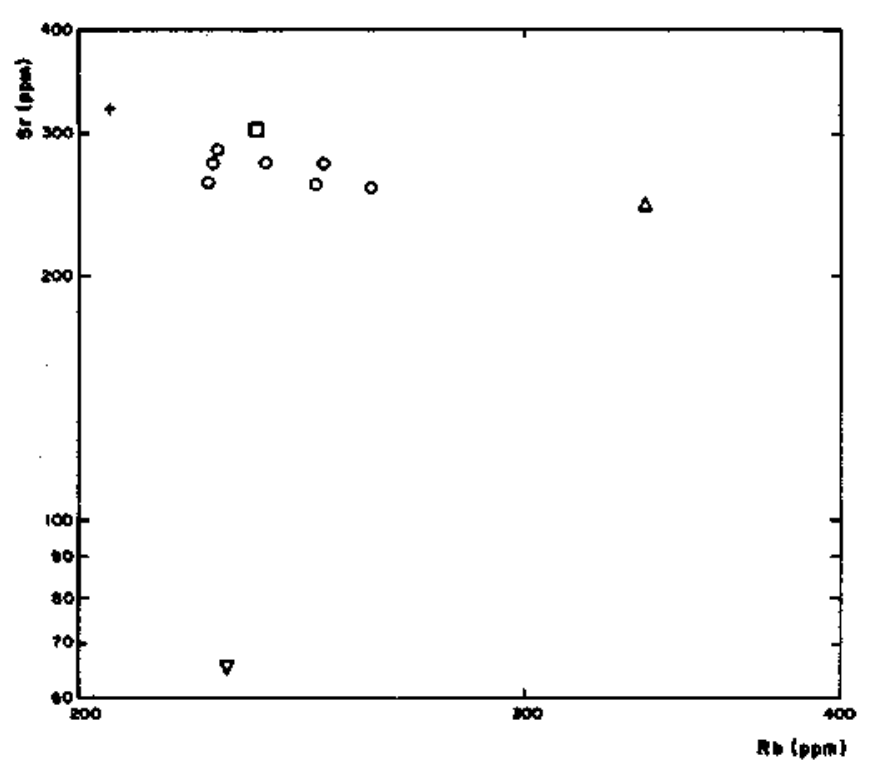

Figura 7 - Diagrama Sr x Rb do Granito Rio Uaupés Figure 7 - Sr-Rb plot of the Rio Uaupés Granite

e Y são baixos. Nessas rochas, o comportamento de $\mathrm{Rb}$ e $\mathrm{Sr}$ não condiz com o esperado, supondo que as mesmas representem produtos de cristalização de líquidos diferenciados a partir do magma gerador dos TBMG. A amostra UA-23 possui a mais baixa razão $\mathrm{Rb} / \mathrm{Sr}$ do conjunto estudado e a U A14 , embora com alta razão $\mathrm{Rb} / \mathrm{Sr}$ e baixo teor de $\mathrm{Sr}$, tem teor de $\mathrm{Rb}$ igual ou inferior aos dos TBMG.
$\mathrm{O}$ diagrama $\mathrm{Sr}-\mathrm{Rb}$ (Fig. 7) sugere tendência a ligeiro aumento de $\mathrm{Rb}$ com a diminuição do $\mathrm{Sr}$; um exame mais cuidadoso mostra, para teores mais ou menos constantes de $\mathrm{Sr}$, variações significativas em $\mathrm{Rb}$, as quais não são facilmente explicáveis pelas composições modais. O comportamento anômalo das amostras U A-14 e UA-23 fica bem evidente nesse diagrama.

As razões $\mathrm{Ca} / \mathrm{Sr}$ e $\mathrm{K} / \mathrm{Rb}$ (Tab.l) apresentam variações muito discretas nos TBMG e dentro dos valores considerados normais em granitos. Os LMG possuem razões $\mathrm{K} / \mathrm{Rb}$ similares às dos TBMG, enquanto aquela do LSG é muito elevada. As razões $\mathrm{Ca} / \mathrm{Sr}$ são variáveis nos $\mathrm{LMG}$ e LSG e, em dois deles, nitidamente inferiores às dos TBMG.

Em relação a outros granitos da Amazônia (Dali'Agnol et al. 1987, Figs. 14 e 15), o Granito Rio Uaupés separa-se claramente dos demais no diagrama $\mathrm{Sr}-\mathrm{Rb}$, num paralelismo evidente ao observado no diagrama $\mathrm{CaO}-\mathrm{K}_{2} \mathrm{O}$. Já, no diagrama K-Rb (Fig. 8), o Granito Rio Uaupés situa-se no domínio das razões mais comuns em rochas crustais, tendo razões similares às de vários outros granitóides, embora comparativamente enriquecido em potássio.

Nos diagramas $\mathrm{Rb}-(\mathrm{Y}+\mathrm{Nb})$ e Nb-Y (Figs. 9a,b; campos definidos por Pearce et al. 1984), os TBMG e o BGD incidem no campo dos granitos intraplaca; os LMG e LSG apresentam um comportamento distinto. A amostra UA-13 (LMG) na realidade difere dos TBMG apenas em função do seu menor conteúdo de $\mathrm{Nb}$. As amostras UA-23 e UA-14 podem ter sua incidência nos campos dos granitos de arcos vulcânicos e sincolisionais explicada simplesmente pelo fato de serem muito ricas em silica e, consequentemente, empobrecidas em Y e Nb (em rochas muito evoluídas, tal comportamento foi previsto por Pearce et al. 1984). Concluindo, esse diagrama sugere que os TBMG formaram-se em ambiente intraplaca ou, alternativamente, que a sua composição química é similar, com base nos elementos considerados, à dos granitos fanerozóicos formados nesse ambiente.

Os resultados das análises de elementos terras raras (Tab. 3) e os padrões de distribuição correspondentes (Fig. 10) mostram-se muito similares para os TBMG e BGD e claramente distintos para o LMG (UA-13) e LSG. Os teores de terras raras nos primeiros ( 240 e 300 ppm) são similares aos geralmente encontrados em granitos com 60 a $70 \%$ de $\mathrm{SiO}_{2}$ (Haskin et al. 1968). As anomalias negativas de európio são pequenas a moderadas $\left(\mathrm{Eu} / \mathrm{Sm}=0,16\right.$ a 0,$18 ; \mathrm{Eu} / \mathrm{Eu}^{*}=0,56$ a 0,62; cf. Cullers \& Graf 1984, p. 293) e o fracionamento das TRL é importante (razões $[\mathrm{La} / \mathrm{Lu}]_{\mathrm{cn}}$ entre 11,92 e 22,55$)$. O BGD apresenta anomalia de európio similar as dos TBMG $\left(\mathrm{Eu} / \mathrm{Eu}^{*}=0,58\right)$, apesar de sua proporção mais elevada de plagioclásio modal.

No LMG (UA-13), são notáveis o enriquecimento relativo em terras raras $(\mathrm{TR}=490 \mathrm{ppm})$, o ligeiro aumento da anomalia negativa em európio $\left(\mathrm{Eu} / \mathrm{Eu}^{*}=0,54\right)$ e a existência de anomalia negativa de cério. Deixando-se esta de lado, o padrão do LMG é similar aos dos TBMG e BGD, mas enriquecido em terras raras. Portanto, o LMG foge à tendência normal verificada durante a diferenciação magmática em rochas graníticas que é, a partir de um certo teor de $\mathrm{SiO}_{2}$, coincidente com o decréscimo das proporções modais de minerais acessórios, dar-se a diminuição do conteúdo de terras raras (Cullers \& Graf 1984, p.298). O excepcional enriquecimento nestes elementos no LMG pode ser explicado em parte pela presença de allanita. Porém, sendo tal mineral um concentrador de terras raras leves (Henderson 1984, sua Fig. 1.14; Fourcade \& Allègre 1981, sua Fig. 7b), é difícil justificar a ausência de fracionamento mais intenso nessa amostra $\left([\mathrm{La} / \mathrm{Lu}]_{\mathrm{cn}}=19,6\right.$; similar às observadas nos TBMG), a menos que ocorram outras fases minerais ricas em TRP. O zircão não poderia ser considerado, porque o LMG é fortemente empobrecido em zircônio, restando, em razão do teor elevado de ítrio (Tab.l), a hipótese de uma fase rica em Y e TRP(monazita? xenotímio?), a qual, associada a allanita, explicaria a assinatura de terras 


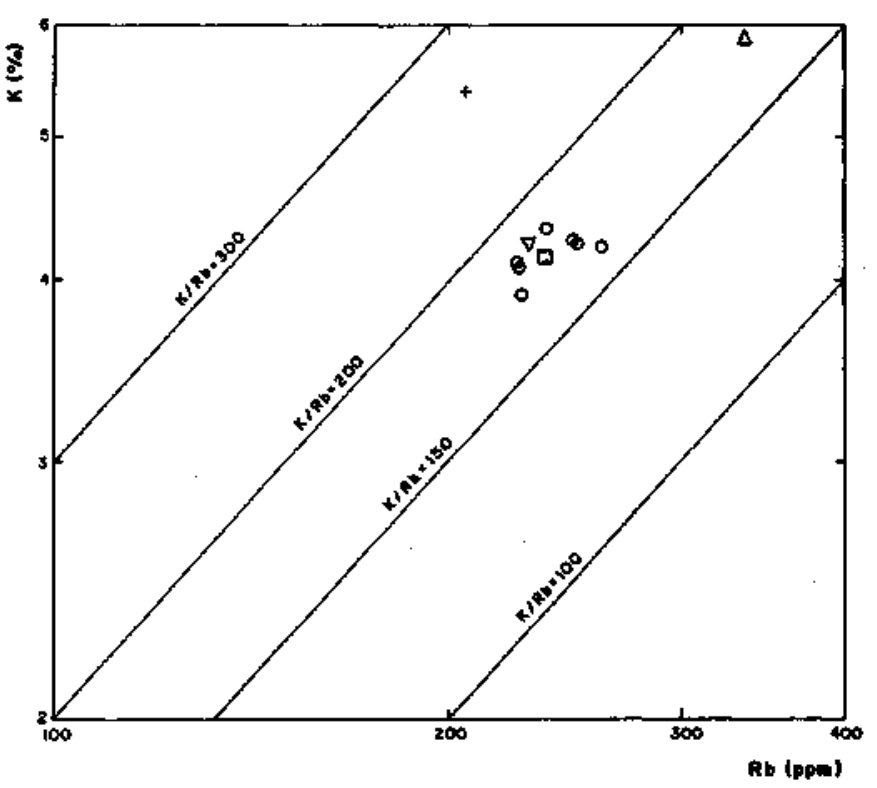

Figura 8 - Diagrama Kx Rb do Graniio Rio Uaupés Figure $8-\mathrm{K}-\mathrm{Rb}$ plot of the Rio Uaupés Granite

raras obtida. A anomalia negativa de cério também é feição incomum (a hipótese de problema analítico foi testada, repetindo a análise da amostra, e confirmpu-se o resultado inicial). Considerando a notável semelhança geoquímica entre os elementos terras raras leves, é difícil supor fracionamento seletivo de cério em relação à lantânio, neodímio e samário. A única explicação plausível seria admitir que fases cristalizadas anteriormente tivessem consumido mais cério que os demais TRL, empobrecendo o líquido residual no primeiro. A apatita é uma fase precoce na cristalização dos TBMG e poderia desempenhar esse papel, desde que se admita que a mesma possua anomalias positivas de cério. Tal fato já foi verificado em rochas da Amazônia (Lemos 1990), mas não é feição constante na apatita (cf. Fourcade \& Allègre 1981, sua Fig. 7a; Henderson 1984, sua Fig. 1.14), Essa hipótese precisaria ser testada por meio de análises de terras raras nas fases acessórias e, particularmente, na apatita.

O LSG apresenta assinatura (Fig. 10) que contrasta com as dos TBMG e BGD, em razão da sua anomalia positiva em európio e dos baixos teores em terras raras, similares aos obtidos em monzogranitos e sienogranitos com tais anomalias (Cullers \& Graf 1984, sua Fig. 8.8b). Essa amostra, apesar do seu caráter hololeucocrático, possui um plagioclásio de composição similar ao observado em certas amostras de TBMG. Além disso, esse plagioclásio mostra transformação pouco usual. O LSG tem, ainda, os teores mínimos de Rb, $\mathrm{Y}$ e $\mathrm{Nb}$ e máximo de Sr do conjunto analisado (Tab. 1). Uma hipótese para explicar tais aspectos seria a de que tal rocha represente agregado de cristais félsicos similar aos presentes nos TBMG, praticamente desprovido de fases máficas, talvez associado a pequena fração de fusão ou de líquido residual. Esse último aspecto justificaria o empobrecimento em terras raras. A presença de plagioclásio relativamente cálcico causaria o enriquecimento relativo em európio (é importante notar que os teores absolutos de európio são menores que nas demais variedades). Ela também pode explicar em parte os elevados teores de $\mathrm{Sr}$, mas, considerando os baixos conteúdos modais de plagioclásio, é preciso admitir que outras fases (feldspato alcalino?) sejam igualmente ricas nesse elemento ou que o plagioclásio dessa amostra tenha sido particularmente enriquecido em $\mathrm{Sr}$.

Dentre as seis amostras analisadas para TR, cinco (2 TBMG, 1 BGD, 1 LMGe 1 LSG) foram submetidas a análises isotópicas e todas mostram excelente alinhamento no diagrama isocrônico Rb-Sr (Dali'Agnol \& Macambira 1992). Considerando esse aspecto e as semelhanças petrográficas e geoquímicas - em particular, a concordância nos padrões de TR -, é legítimo assumir a cogeneticidade entre os TBMG e BGD. Quanto ao LMG, apesar do seu padrão particular de terras raras, a hipótese de cogeneticidade com os TBMG e BGD é ainda a mais aceitável, embora não se possa afirmar que o mesmo represente um produto de diferenciação magmática do líquido gerador dos TBMG. Finalmente, no que tange ao LSG, a petrografia e o seu alinhamento na isócrona sugerem a sua ligação evolutiva com os TBMG; porém, o comportamento de seus elementos traços não condiz com a hipótese de que os mesmos correspondam a produtos da cristalização de líquidos residuais derivados dos magmas geradores das demais fácies. O LSG possui certamente uma

Tabela 3 - Concentrações de elementos terras raras no Granito Rio Uaupés

Table 3 - Rare earth element contents of Rio Uaupés Granite

\begin{tabular}{|c|c|c|c|c|c|c|c|c|c|c|c|c|c|c|c|c|c|}
\hline AMOSTRA & La & $\mathrm{Ce}$ & Nd & $\mathrm{sm}$ & Bu & Gd & Dy & $\mathbf{H o}$ & Ex & $\mathbf{Y b}$ & Lu & ST & Eursin & $(\mathrm{LNL}) \mathrm{ON}$ & $(\mathrm{La} / \mathrm{Sm}) \mathrm{CN}$ & $(\mathrm{Gd} / u) \mathrm{CN}$ & EwEn* \\
\hline \multirow[t]{2}{*}{ UAEV_CB } & 60.44 & 11330 & 58,41 & 10.80 & 1,97 & 8.26 & 6.52 & 1,43 & 4,06 & 395 & 050 & 296,64 & 0,18 & 1209 & 3,21 & 2,16 & 0,64 \\
\hline & 177,76 & 146,48 & 91,27 & 55,38 & 26.99 & 31.77 & 21.73 & 18,33 & 20,30 & 17,99 & 14,70 & & & & & & \\
\hline & & & & & & & & & & & & & & & & & \\
\hline \multirow[t]{2}{*}{ UAEV_-20 } & 66,43 & 122,10 & 66,59 & 12,0 & 2,09 & 9,56 & 7,17 & 1,64 & 4,36 & 3,98 & 0,52 & $\mathbf{2 6 , 4 4}$ & 0.17 & 12,78 & 3,17 & 1.87 & 0,38 \\
\hline & 195,38 & 134,18 & 104.05 & 61,54 & 28,63 & 37,77 & 23,90 & 21,02 & 21,80 & 18,09 & 15,29 & & & & & & \\
\hline & & & & & & & & & & & & & & & & & \\
\hline \multirow[t]{2}{*}{ UAEV-1I } & 54,81 & 106.30 & 49.17 & 8.90 & 1.63 & 6.92 & 5.43 & 1.29 & 3.49 & 3,13 & 0,46 & 24,53 & 0.18 & 11,92 & 3,53 & 1,97 & 0,62 \\
\hline & 161,21 & {$[16.81$} & 76,83 & 45,64 & 22,33 & 26,62 & 18,10 & 16.54 & 17,45 & 14,23 & 13,53 & & & & & & \\
\hline \multirow[t]{2}{*}{ UAEV-A! } & $\mathbf{5 4 , 1 0}$ & 102,30 & 57,15 & 10,80 & 1,78 & 8,38 & 580 & 1,20 & 2,77 & 1,81 & 024 & 246,33 & 016 & 22,55 & 2,87 & 4,57 & 0,56 \\
\hline & 199,18 & 112,42 & 89,30 & 55,38 & 24,38 & 32,23 & 19,33 & 15,38 & 13,85 & 8,23 & 7,06 & & & & & & \\
\hline \multirow[t]{2}{*}{ UAEV-13 } & 180,65 & 77.75 & 143.90 & 25.90 & 4,15 & 20,27 & 17,20 & 3.30 & 8.83 & 7,68 & 0.92 & 40.55 & 0.16 & 1963 & 4,00 & 288 & 0,54 \\
\hline & 531,32 & 85,44 & 224,84 & 132,82 & 56,85 & 77,96 & 57,33 & 42,30 & 44,15 & 34,90 & 27,06 & & & & & & \\
\hline & & & & & & & & & & & & & & & & & \\
\hline \multirow[t]{2}{*}{ UAEV-23 } & 18,07 & 28.38 & 1236 & 1,97 & 1,14 & 1.42 & 0,98 & 0,20 & 0.52 & 0.47 & 0,10 & 65.61 & 058 & 18,08 . & 5,32 & 1.86 & 2,02 \\
\hline & 53,15 & 31,19 & 19,31 & 10,10 & 15,62 & 5,46 & 3,27 & 2,56 & 260 & 2,14 & 294 & & & & & & \\
\hline
\end{tabular}

Ia linha - teores em ppm; 2" linha - teores normalizados em relação aos condntos (Wakita et al. 1971); análises da GEOSOL. 
história complexa, não inteiramente compreensível a partir dos dados disponíveis.

As assinaturas de terras raras dos TBMG e BGD merecem ainda algumas consideraç̃es: $\mathbf{I}$. $\mathrm{O}$ acentuado enriquecimento relativo em terras raras leves, embora reflita características intrínsecas do magma, foi favorecido pela formação de titanita e apatita, que concentram preferencialmente tais elementos (Fourcade \& Allègre 1981, sua Fig. 7a e Tab. 3). 2. O grau de fracionamento e o relativo empobrecimento em TRP sugere a separação ou a presença no resíduo de fusão de fases concentradoras desses elementos, tais como hornblenda, clinopiroxênio e granada. 3. As pequenas a moderadas anomalias negativas de európio indicam que não houve extenso fracionamento de plagioclásio ou concentração elevada desse mineral no resíduo. Outra possibilidade, considerada por Cullers \& Graf $(1984$, p. 293), por causa da existência de anomalia negativa de európio na hornblenda e positiva no plagioclásio (Fourcade \& Allègre 1981, sua Fig. 7a), é admitir que hornblenda e parte do plagioclásio separaram-se nos primeiros líquidos magmáticos ou concentraram-se no resíduo de fusão, em proporções tais que não permitiram empobrecimento relativo em európio acentuado no líquido gerador dos TBMG e BGD.

\section{COMPARAÇÕES COM OUTROS GRANITÓIDES}

Considerando a hipótese de que a Província Rio Negro corresponda a uma zona de colisão e as características geoquímicas do Granito Rio Uaupés discutidas anteriormente, inicialmente, foi feita a opção por estabelecer comparações entre o mesmo e granitos representativos de zonas de colisão continental. Por outro lado, o caráter subalcalino potássico destes granitos e a sua idade conduzem a uma comparação com granitóides das séries shoshoníticas e com os granitos rapakivíticos do Proterozóico Médio da América do Norte e Escudo Báltico. Dados analíticos representativos desses diferentes granitóides foram selecionados na bibliografia, procurando-se, no possível, rochas com teores de silica similares aos observados nos TBMG (Tab. 4).

No diagrama de variação de elementos normalizados do granito de cadeia oceânica (ORG) (Pearce et al. 1984), é constatado que o padrão definido pelos TBMG e BGD (Fig. 11) é distinto do apresentado pelos granitóides sin-colisionais e de arco-vulcânico, todos comparativamente empobrecidos em Nb, Zr, Y e TR, em relação ao Granito Rio Uaupés. O mesmo é válido para $\mathrm{Rb}$ e $\mathrm{K}_{2} \mathrm{O}$, exceto no caso dos granitos sin-colisionais, muito ricos nesses elementos. Os granitos intraplaca, representados por aqueles do Rift de Oslo e das Ilhas Ascensão, são, ao contrário, bem mais ricos em Nb, Zr, Y e TR que o Granito Rio Uaupés. Sobre esses elementos, há notável semelhança entre o último e os granitos intraplaca de litosfera continental atenuada, exemplificados por granitos associados às intrusões de Skaergaard e Mull. Entretanto, esses granitos, apesar de seus teores bastante elevados de $\mathrm{SiO}_{2}$, são muito mais pobres em $\mathrm{K}_{2} \mathrm{O}$ e $\mathrm{Rb}$ (Cf. Pearce et al. 1984, sua Tab. 2) que os TBMG.

Esse diagrama sugere diferenças geoquímicas expressivas entre o Granito Rio Uaupés e os granitos colisionais e de arcos vulcânicos. Em relação aos granitos intraplaca, os contrastes são menos marcantes. Porém não existe tampouco uma perfeita correspondência. Esse raciocínio é válido apenas para os exemplos escolhidos por Pearce et al. (1984) como representativos dos diferentes ambientes tectônicos e é óbvio que nem todos os tipos de magmatismo foram por eles considerados. Além disso, tais autores usaram exclusivamente granitos do Fanerozóico e podem existir diferenças em relação a rochas pré-cambrianas.

Granitóides de zonas de colisão Harris et al. (1986) discutiram as características geoquímicas do magmatismo em zonas de colisão, distinguindo quatro grupos de intrusões: 1. intrusões cálcio-alcalinas de arco vulcânico pré-colisão; 2. leucogranitos peraluminosos sin-colisão; 3. intrusões cálcio-alcalinas tardi ou pós-colisão; 4 . intrusões alcalinas pós-colisão. Debon et al. (1986) sintetizaram diferentes aspectos dos quatro cinturões plutônicos transhimalaianos. Os granitoides herciniamos dos Pirineus e da Peninsula Ibérica são tradicionalmente utilizados como exemplos de granitóides de zonas de colisão (Pearce et al. 1984, Harris et al. 1986). Análises representativas de granitóides de zonas de colisão constam da tabela 4.

Harris et al. (1986, p. 69) consideram a suíte granítica trans-himalaiana como representativa do grupo 1. Porém, Debon et al $(1986$, p.229) afirmam, com base em argumentos convincentes, que a maioria das rochas dessa suíte é tipicamente subalcalina (isto é, monzonítica) ou transicional entre tipos subalcalinos e cálcio-alcalinos, não havendo associação estritamente cálcio-alcalina na mesma (Debon et al. 1986, sua Tab. 2 e p.230). De qualquer modo, a composição química da rocha selecionada (Tab. 4) da suíte trans-himalaiana (Adamelito Gu Rong) diverge dos TBMG pelos teores mais elevados de $\mathrm{MgO}$ e, em menor grau, $\mathrm{Na}_{2} \mathrm{O}$, e inferiores de $\mathrm{TiO}_{2}, \mathrm{~K}_{2} \mathrm{O}, \mathrm{P}_{2} \mathrm{O}_{5}, \mathrm{Rb}, \mathrm{Y}$ e TR. As assinaturas de TR são semelhantes; porém, o fracionamento de TRP parece mais importante no TBMG. Além dessas diferenças geoquímicas, o Granito Rio Uaupés diverge da suíte mencionada pelo seu caráter pós-deformação (pós-tectônico ou pós-colisional?).

O grupo 2 consiste essencialmente de leucogranitos sinorogênicos, com muscovita, geralmente associada a biotita e turmalina, como os granitos do Alto Himalaia e os granitos sintectônicos hercinianos. O Adamelito de Manaslu (Tab. 4) é representativo desse grupo. E evidente que não existe afinidade geoquímica entre tais granitos e o Granito Rio Uaupés, pois os primeiros são da série a ilmenita, peraluminosos, do tipo $\mathrm{S}$, relativamente pobres em $\mathrm{CaO}, \mathrm{TiO}_{2}$ e TR e, geralmente, apresentam fortes anomalias negativas de európio. Na Província Rio Negro, os granitos similares ao Adamelito Manaslu são aqueles com duas micas do Rio Içana (Dall'Agnol et al. 1987).

O Maciço do Quérigut nos Pirineus (Leterrier 1972, Marre 1973) e os Younger Gran ites do Norte de Portugal (A Ibuquerque 1978) são tomados como exemplos do grupo 3 (Tab. 4). A suíte do Quérigut é tipicamente cálcio-alcalina (Leterrier 1972, Fourcade \& Allègre 1981) e diferencia-se dos TBMG pelos conteúdos de $\mathrm{TiO}_{2}, \mathrm{Al}_{2} \mathrm{O}_{3}, \mathrm{CaO}, \mathrm{Na}_{2} \mathrm{O}, \mathrm{K}_{2} \mathrm{O}, \mathrm{Rb}$, Sr e TR. $\mathrm{Na}$ assinatura de TR dos monzogranitos desse macico (Fourcade \& Allègre 1981), é notável a ausência de anomalia de európio, contrastando com o TBMG (Fig. 10). Quanto aos granitos de Portugal, há semelhanças importantes com os TBMG nos conteúdos de álcalis, razão $\mathrm{FeO},(\mathrm{FeO},+\mathrm{MgO}), \mathrm{Sr}$ e na assinatura dos elementos terras raras (Albuquerque 1978). Porém, os primeiros são relativamente enriquecidos em $\mathrm{Al}_{2} \mathrm{O}_{3}$ e empobrecidos em $\mathrm{CaO}$, o que se reflete na sua associação modal com muscovita primária, sillimanita ou andalusita, apatita, zircão, ilmenitaimonazita, tipicamente peraluminosa e similar à encontrada em granitos do tipo $\mathrm{S}$ (White \& Chappell 1977).

O grupo 4 é discutido por Harris et al. (1986) de modo muito sucinto, não sendo fornecido nenhum exemplo da categoria. Esses autores afirmam apenas que o magmatismo seria alcalino e com características geoquímicas do tipo intraplaca. $\mathrm{O}$ fato do Granito Rio Uaupés incidir no campo dos granitos intraplacas em certos diagramas (Figs. 9a,b) poderia ser visto como indicativo de sua vinculação a esse grupo. Porém tal conclusão é prematura.

Portanto, o Granito Rio Uaupés não apresenta características geoquímicas similares às dos granitos colisionais fanerozóicos aqui tomados como exemplo.

Granitóides subalcalinos potássicos e/ou shoshoníticos Embora as associações shoshoníticas sejam, em geral, subalcalinas e potássicas, o inverso não é verdadeiro. Revisões sobre as primeiras foram apresentadas por 
Tabela 4 - Comparação entre a composição geoquimica do Granito Rio Uaupes e aquelas de diversos granitoides representativos de diferentes ambientes tectónicos

Table 4 - Geochemical comparison between Rio Uaupés Granite and granites formed in different tectonic settings

\begin{tabular}{|c|c|c|c|c|c|c|c|c|c|c|c|c|c|c|c|c|c|c|}
\hline & \multicolumn{5}{|c|}{ COLISHONAIS } & \multicolumn{4}{|c|}{$\begin{array}{c}\text { SUBALCALIMOS EKOU } \\
\text { SHOSHONITICOS }\end{array}$} & \multicolumn{7}{|c|}{ ASSOCIACOES RAPAKNTICAS } & \multicolumn{2}{|c|}{$\begin{array}{l}\text { GRANITO } \\
\text { UAUPES }\end{array}$} \\
\hline & \multicolumn{2}{|c|}{ HMALAIA1 } & \multicolumn{2}{|c|}{ QUERIGUT2-3 } & \multirow{3}{*}{ 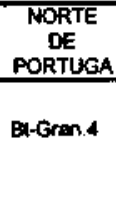 } & \multirow{3}{*}{ 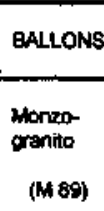 } & \multirow{3}{*}{$\begin{array}{l}\text { CRÉES } \\
\text { Granito } \\
\text { Aull } \\
\text { (MiN10) }\end{array}$} & \multirow{3}{*}{$\begin{array}{l}\text { PLOUMAMACH } \\
\text { Grom } \\
\text { Ponf. } \\
\text { Troouidros } \\
\text { (G 2) }\end{array}$} & \multirow{3}{*}{$\begin{array}{l}\text { LAVRAS } \\
\text { Granod. } \\
206\end{array}$} & \multicolumn{2}{|c|}{ LATILAG } & \multicolumn{2}{|c|}{ WOLF RNEF } & \multicolumn{3}{|c|}{$\begin{array}{c}\text { SUDOESTE DOS } \\
\text { ESTADOS UNIDOS10 }\end{array}$} & \multirow{3}{*}{$\begin{array}{l}\text { TaM } \\
(M)^{*}\end{array}$} & \multirow{3}{*}{$\begin{array}{l}\text { LMG } \\
\text { (UA-13) }\end{array}$} \\
\hline & $\begin{array}{l}\text { Trant- } \\
\text { Hinat } \\
\text { Adamet } \\
\text { Gutong }\end{array}$ & $\begin{array}{l}\text { Allo } \\
\text { Minnol. } \\
\text { Mentulu } \\
\text { Adsm. }\end{array}$ & $\begin{array}{l}\text { Morian } \\
\text { granta }\end{array}$ & $\begin{array}{l}\text { Horize- } \\
\text { Qranito } \\
\text { Portir. }\end{array}$ & & & & & & $\begin{array}{l}\text { Gran } \\
\text { Tarkiki }\end{array}$ & $\begin{array}{l}\text { Gren. } \\
\text { Repeld. } \\
\text { Nomral }\end{array}$ & $\begin{array}{l}\text { Adangl } \\
\text { Waupec }\end{array}$ & $\begin{array}{l}\text { Gren } \\
\text { Wot } \\
\text { Phroer }\end{array}$ & $\begin{array}{l}\text { Gold } \\
\text { Butt. }\end{array}$ & $\begin{array}{l}\text { Beor } \\
\text { Botlla }\end{array}$ & Nowpeny & & \\
\hline & & $(M 190)$ & $(M g 2)$ & $(M \mathbf{3 6})$ & & & & & & & (M 14) & & & (MB) & (M 3) & $(\mathbf{M} 3)$ & & \\
\hline $\mathrm{SiO}^{2}$ & 67.74 & 73,69 & 68,10 & 68,60 & 68,31 & 66.07 & 34,90 & 67,80 & 69,44 & 65,87 & 68,99 & 67,29 & 73,30 & 69,60 & 66,81 & 64,62 & 67,2 & 72,68 \\
\hline $\mathrm{THO}^{2}$ & 0,53 & 0,09 & 0,38 & 0,40 & 0,68 & 0,44 & 0,85 & 0,65 & 0,30 & 0,79 & 0,58 & 0,70 & 0,31 & 0,75 & 1,02 & 1.30 & 0,82 & 0,27 \\
\hline Al:O: & 14,77 & 14,85 & 15,85 & 15,35 & 15,95 & 14,52 & 13,40 & 14,57 & 15,72 & 13,61 & 14,51 & 14,19 & 13,18 & 14,20 & 14,36 & 13,88 & 14,7 & 14,51 \\
\hline $\mathrm{Fe}: \mathrm{O}$ & $4.25^{*}$ & $0.84^{*}$ & $3,09^{*}$ & $2,86^{*}$ & 0,30 & $3,59^{*}$ & $5,35^{*}$ & $3.51^{*}$ & 0,54 & 1,68 & 0,68 & $4,36^{*}$ & $2,67^{*}$ & $3,7^{*}$ & $4,87^{*}$ & $6,03^{*}$ & 4,54 & $1,28^{*}$ \\
\hline Feo & - & * & $=$ & - & 2.83 & $=$ & - & $\cdot$ & 2,04 & $\mathbf{5 . 4 9}$ & 3.99 & - & $=$ & $=$ & - & - & - & - \\
\hline MnO & 0,08 & 0.03 & 0,05 & 0.05 & 0.06 & 0,07 & 0.09 & 0.04 & 0.04 & 0.08 & 0.05 & 0,081 & 0.052 & 0.07 & 0,098 & 0,104 & 0.09 & 0.05 \\
\hline $\mathrm{MgO}$ & 1,30 & 0.11 & 1,02 & 1.09 & 0,86 & 2.16 & 4,56 & 1.05 & 0.61 & 0,75 & 0.50 & 0.57 & 0,24 & 0,64 & 0,67 & 1,47 & 0.83 & 0.25 \\
\hline $\mathrm{CaO}$ & 3.23 & 0.47 & 2,70 & 2,87 & 1,82 & 2,78 & 3,17 & 1,92 & 1,69 & 1,98 & 2,20 & 1.93 & 1,09 & 1,92 & 2.74 & 3.46 & 3,13 & 1,26 \\
\hline $\mathrm{NaO}$ & 3,20 & 4,05 & 3,55 & 3.47 & 3,22 & 3,18 & 2.23 & 3,41 & 4,69 & 2,43 & 2,68 & 3,16 & 3,13 & 2,94 & 2,69 & 2.77 & 2,88 & 2,6 \\
\hline$K_{2}=0$ & 4,22 & 4,55 & 3,78 & $3, \mathrm{BB}$ & 5,06 & 5,12 & 4,71 & 5,35 & 3,46 & 4,67 & 5,24 & 5,82 & 5,24 & 5,51 & 4,83 & 3,88 & 5,02 & 7,67 \\
\hline$P=0$ & 0,14 & 0.13 & $=$ & - & 0,27 & - & - & $=$ & 0,08 & 0,30 & 0,09 & . & * & - & - & * & 0,29 & 0,07 \\
\hline $\mathrm{Fb}$ & 178 & 367 & 155 & 170 & - & 333 & - & 324 & 112 & 183 & 192 & 189 & 179 & 246 & 190 & 180 & 299 & 335 \\
\hline $\mathrm{sr}$ & 244 & 75 & 165 & 155 & 270 & 410 & - & 371 & 849 & 211 & $1 \$ 2$ & 170 & 88,6 & 239 & 290 & 279 & 271 & 248 \\
\hline$z$ & - & - & - & - & $=$ & $230^{+m}$ & 489 & $*$ & 181 & 607 & 392 & * & $=$ & 304 & 390 & 397 & 308 & 77 \\
\hline$Y$ & 28,9 & 11,44 & - & - & - & - & $=$ & . & 14 & * & - & * & - & 54,6 & 56,3 & 60,0 & 71 & 210 \\
\hline $\mathrm{Nb}$ & . & - & $=$ & . & $=$ & - & $=$ & - & 17 & - & - & - & - & 33,9 & 29,8 & 30,0 & 25 & 13 \\
\hline La & 23,53 & 8,19 & 36.7 & 32,8 & 53,5 & $37^{x=}$ & 50,1 & - & 38,60 & 82 & 66 & 119 & 101 & 111 & 75,6 & 32,2 & 56,5 & 180,7 \\
\hline $\mathrm{Ce}$ & 46.65 & 12,28 & 62 & 56.8 & 121 & - & 94,6 & - & 53,20 & 193 & 161 & 257 & 199 & * & * & - & 107. & 77,8 \\
\hline Nod & 22,43 & 4,74 & 32 & 29,7 & 55 & . & 68 & - & 22,40 & 107 & 74 & - & . & $\cdot$ & . & $\cdot$ & 54,8 & 143,9 \\
\hline ST & 4,55 & 1,46 & 5,0 & 4.7 & 8,4 & - & 11,5 & - & 4,30 & 16.9 & 11,2 & 18,4 & 16,5 & $=$ & * & - & 10,2 & 25,9 \\
\hline Eu & 0.80 & 0,28 & 0,95 & 1,02 & 0,75 & $1.2^{* * *}$ & 1,8 & - & 0,74 & 2,75 & 2.19 & 3.23 & 2,25 & - & - & - & 1,8 & 4,2 \\
\hline Gd & 3,93 & 1,59 & . & - & 6.2 & $\cdot$ & - & . & 3,15 & . & 12,7 & 21 & 18,4 & - & - & - & 7,8 & 20,3 \\
\hline$T$ & - & - & 0.7 & 0,55 & 0,65 & $0.53^{+1}$ & 0,75 & $\cdot$ & $\cdot$ & 2,7 & 1,81 & 2,62 & 2,34 & . & - & - & - & * \\
\hline Dy & 4,02 & 1,92 & $=$ & - & 3,0 & - & $=$ & $\cdot$ & 2,36 & 16.7 & 13.6 & - & - & . & - & $\cdot$ & 5,9 & 17,2 \\
\hline Ho & - & $=$ & $\cdot$ & - & 0.55 & $=$ & $=$ & $\cdot$ & 0,56 & - & - & 4,09 & 3,24 & - & - & - & 1,3 & 3,3 \\
\hline Er & 2.43 & 0.70 & $=$ & - & 1,45 & - & - & , & 1,57 & . & - & - & - & - & - & - & 3,4 & 8.8 \\
\hline$r b$ & 2.49 & 0,64 & 1.95 & 1,32 & 1,15 & . & 1.8 & - & 0,99 & 8,8 & 5,24 & 8,97 & 6,79 & - & - & - & 2,96 & 7,60 \\
\hline يسا| & 0,39 & 0,10 & 0.34 & 0,33 & $=$ & $=$ & 0,36 & . & 0.20 & 1.3 & $<0,3$ & 1,38 & 1,15 & - & - & - & 0,4 & 0,82 \\
\hline
\end{tabular}

Morrison (1980) e Nardi (1986), com o último autor enfatizando as características dos granitóides dessa série. Como exemplo de granitóides shoshoníticos (Tab.4) foram usados os Granites de Ballons e Crêtes no Vosges Meridional (Pagel \& Leterrier 1980, Pagel 1982) e o Granito Lavras do Rio Grande do Sul (Nardi \& Lima 1985). Foi adicionado, ainda, o Granito de Ploumanac'h (Tab. 4), por se tratar de um tipo subalcalino potássico, herciniano, tardi-orogênico, que não foi descrito como shoshonítico (Barrière 1977).

O Granito Rio Uaupés possui em comum com associações shoshoníticas (Morrison 1980) seu conteúdo elevado de álcalis e $\mathrm{Rb}$ e as altas razões $\mathrm{K}_{2} \mathrm{O} / \mathrm{Na}_{2} \mathrm{O}$ e $\mathrm{Fe}_{2} \mathrm{O}_{3} / \mathrm{FeO}$. Diverge das mesmas por apresentar forte enriquecimento em Fe e Ti (cf. Figs, 1 b, 3 e 5a). É verificada boa correspondência em relação ao Granito Ballons de álcalis e $\mathrm{CaO}$, mas um contraste extremo em termos das razões $\mathrm{FeO}_{\mathrm{t}} /\left(\mathrm{FeO}_{\mathrm{t}}+\mathrm{MgO}\right)$ e do conteúdo de $\mathrm{TiO}_{2}$ (Tab. 4). Já, o Granito Ploumanac'h, embora possua razões $\mathrm{FeO}_{\mathrm{t}} /\left(\mathrm{FeO}_{\mathrm{t}}+\mathrm{MgO}\right)$ análogas àquelas observadas no Granito Rio Uaupés (Fig. 5a), distingue-se deste pelos baixos teores de $\mathrm{Ca}$ e (Fe+Mg+Ti). No diagrama R1-R2, os TBMG ocupam carnpo coincidente com o dos monzogranitos de Ballons e distinto daquele do Granito Ploumanac'h; o diagrama $[\mathrm{Mg} /(\mathrm{Fe}+\mathrm{Mg})]$ x B (Figs.4 e 5a) mostra o caráter ferruginoso do Granito Rio Uaupés, similfjr 30 do Maciço 


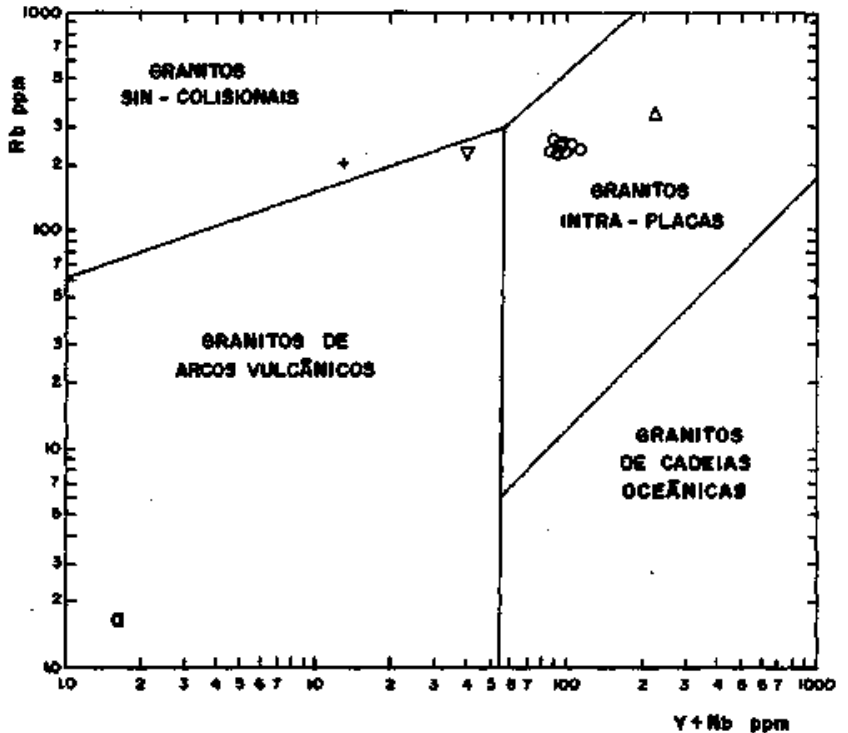

Figura 9 - Distribuição do Granito Rio Uaupés no diagrama NbxY (campos definidos por Pearce et al. 1984)

Figure9b-Nb-Y plot of the Rio Uaupés Granite (fields after Pearcee/a/. 1984)

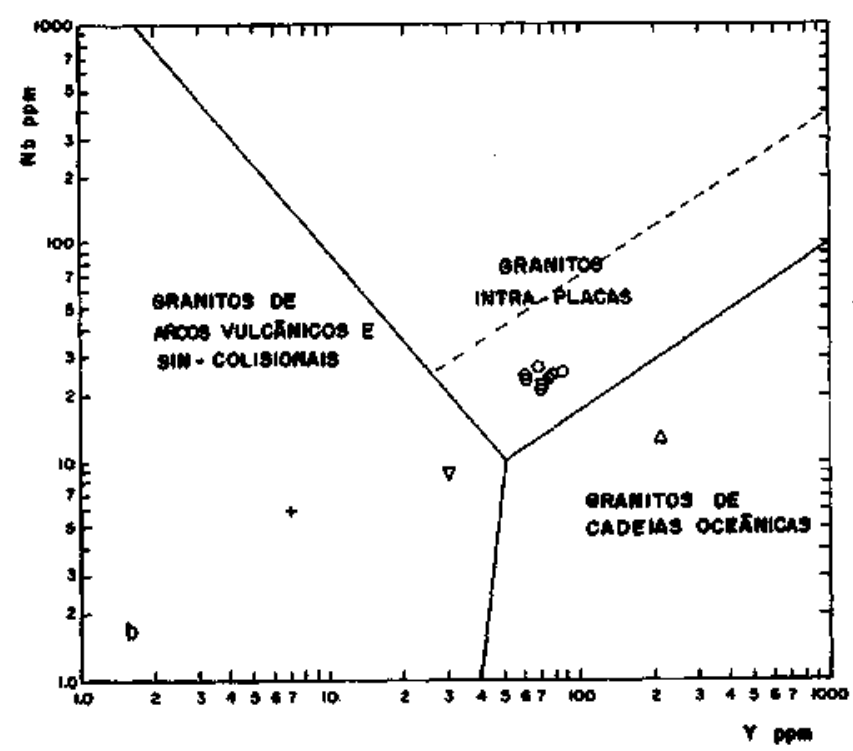

Figura $9 b$ - Distribuição do granito Rio Uaupés no diagrama Nb x Y ( campos definidos por Peace et al. 1984)

Figure $9 b-N b-Y$ plot of the rioUapês Granite (Fields after Pearce et al. 1984)

Ploumanac'h e inteiramente distinto do Maciço Ballons.

Nos elementos traços, as amostras dos Granitos Ballons e Ploumanac'h são mais ricas ern $\mathrm{Rb}$ e $\mathrm{Sr}$ que os TBMG. Quanto aos elementos terras raras, há boa correspondência entre os teores obtidos no Granito de Crêtes (Pagel 1982) e no TBMG, embora a assinatura de TR do primeiro acuse anomalia negativa menos pronunciada de európio. $\mathrm{O}$ padrão de TR dos granitóides da zona central do Maciço Lavras (Nardi \& Lima 1985) também é similar aquele do TBMG, embora sejam observados no último teores mais elevados de TR e fracionamento menos acentuado dos TRP em relação aos TRL.
Resumindo, há diferenças expressivas entre os granitóides shoshoníticos e o Granito Rio Uaupés, com o último sendo mais rico em Ti e Fe e, no caso dos granitóides da zona central do Maciço Lavras, também em $\mathrm{K}_{2} \mathrm{O}, \mathrm{Rb}, \mathrm{Zr}, \mathrm{Nb}$ e $\mathrm{Y}$, e mais pobre em Sr. Há maior semelhança com o Maciço de Ploumanac'h em certos aspectos, mas os contrastes são igualmente marcantes.

Granitóides rapakivíticos e tipos afins São mundialmente conhecidas as ocorrências de granitos rapakivi com cerca de 1.700 a 1.500 Ma no Escudo Báltico, sua área tipo (Nurmi \& Haapala 1986, Haapala \& Ramo 1990). Há, igualmente, na América do Norte, importante província de granitos proterozóicos com idades em torno de 1.100 a $1.500 \mathrm{Ma}$ e afinidades com os granitos do tipo A (Anderson 1983, Van Schmuss et al. 1987). Tanto os primeiros, quanto os últimos, são considerados por alguns autores como anorogênicos (Anderson \& Bender 1989, p. 40) e por outros como póstectônicos (Vorma 1976, p. 85, Maniar \& Piccoli 1989). Tais granitos caracterizam-se pela sua riqueza em $\mathrm{K}_{2} \mathrm{O}$ e por suas altas razões $\mathrm{K}_{2} \mathrm{O} / \mathrm{Na}_{2} \mathrm{O}$ e $\mathrm{FeO}_{t} /\left(\mathrm{FeO}_{\mathrm{t}}+\mathrm{MgO}\right)$. Esses aspectos geoquímicos e as idades, muito similares com aqueles observados no Granito Rio Uaupés, tornam a comparação entre eles importante. Foram tomados como exemplos os granitos rapakivi do Maciço Laitila, na Finlândia (Vorma 1976), o Macico Wolf River (Anderson \& Cullers 1978) e alguns granitóides do sudoeste dos Estados Unidos (Anderson \& Bender 1989).

Os Granitos de Laitila e Wolf River diferem do Granito Rio Uaupés pelos minerais acessórios. Nos primeiros, a fluorita, acompanhada de monazita ou allanita, é um importante mineral acessório, contrariamente à titanita e aos opacos; a faialita costuma ocorrer nas rochas mais ricas em máficos. Tais aspectos sugerem condições de baixa fugacidade de oxigênio durante a cristalização desses granitos, ao passo que, no Granito Rio Uaupés, a associação titanita-magnetitaquartzo (Wones 1989) indica condiçôes de $\mathrm{fO}_{2}$ elevadas.

As associações rapakivíticas mais típicas (Tab. 4) caracterizam-se por teores elevados de $\mathrm{Si}, \mathrm{Rb}, \mathrm{Li}, \mathrm{F}$ e TR (exceto $\mathrm{Eu}$ ) e baixos de $\mathrm{Ca}, \mathrm{Mg}, \mathrm{Al}, \mathrm{Sr}$ e Ba, e por altas razões $\mathrm{Fe} / \mathrm{Mg}$ e baixas razões $\mathrm{Ca} / \mathrm{Na}$ e $\mathrm{K} / \mathrm{Rb}$. Geralmente, apresentam fortes anomalias negativas de Eu (Vorma 1976, Emslie 1978, Anderson \& Cullers 1978). Na maioria dos complexos predominam rochas com teores de $\mathrm{SiO}_{2}$ superiores a $70 \%$. No Granito Rio Uaupés dominam rochas com teores moderados de $\mathrm{SiO}_{2}$; os conteúdos de $\mathrm{Ca}$, Ti e $\mathrm{Sr}$ e as razões $\mathrm{Ca} / \mathrm{Na}$ e K/ $\mathrm{Rb}$ são relativamente elevados; não há evidências de que o flúor desempenhe papel importante na sua evolução; é notado empobrecimento relativo em TR pesadas e anomalias negativas de Eu menos acentuadas, e os constituintes ferromagnesianos são, em geral, mais abundantes. Nurmí \& Haapala (1986, p.215) destacam serem os altos teores de $\mathrm{FeO}, \mathrm{TiO}_{2}$, $\mathrm{P}_{2} \mathrm{O}_{5}$, Sr e Ba uma característica distintiva entre os granitos pós-tectônicos da Finlândia e os granitos rapakivi. Isso sugere que o Granito Rio Uaupés seria geoquimicamente mais próximo dos primeiros. Essas mesmas diferenças são observadas entre o Granito Rio Uaupés e os granitos anorogênicos do tipo A da Província Amazônia Central, do Proterozóico Médio, conforme salientado por DalFAgnol et al. (1987, p.395). Esses autores, contrariamente a Kroonenberg (1981), Priem et al. (1982) e Gaudette \& Olszewski (1985), não defendem correlação entre os granitóides similares ao Granito Rio Uaupés e os granitos rapakivi tipo Parguaza (Mendoza 1975, Gaudette et al. 1978).

Por outro lado, o magmatismo granítico proterozóico do tipo A, do sudoeste dos Estados Unidos, é muito similar geoquimicamente ao Granito Rio Uaupés e aos granitos intraplaca (Cf. Anderson \& Bender 1989, ver análises representativas na Tab. 4). Além disso, as proporções modais de titanita, opacos e apatita também costumam ser muito elevadas nos mesmos. As idades $\mathrm{U} / \mathrm{Pb}$ desses granitos são 


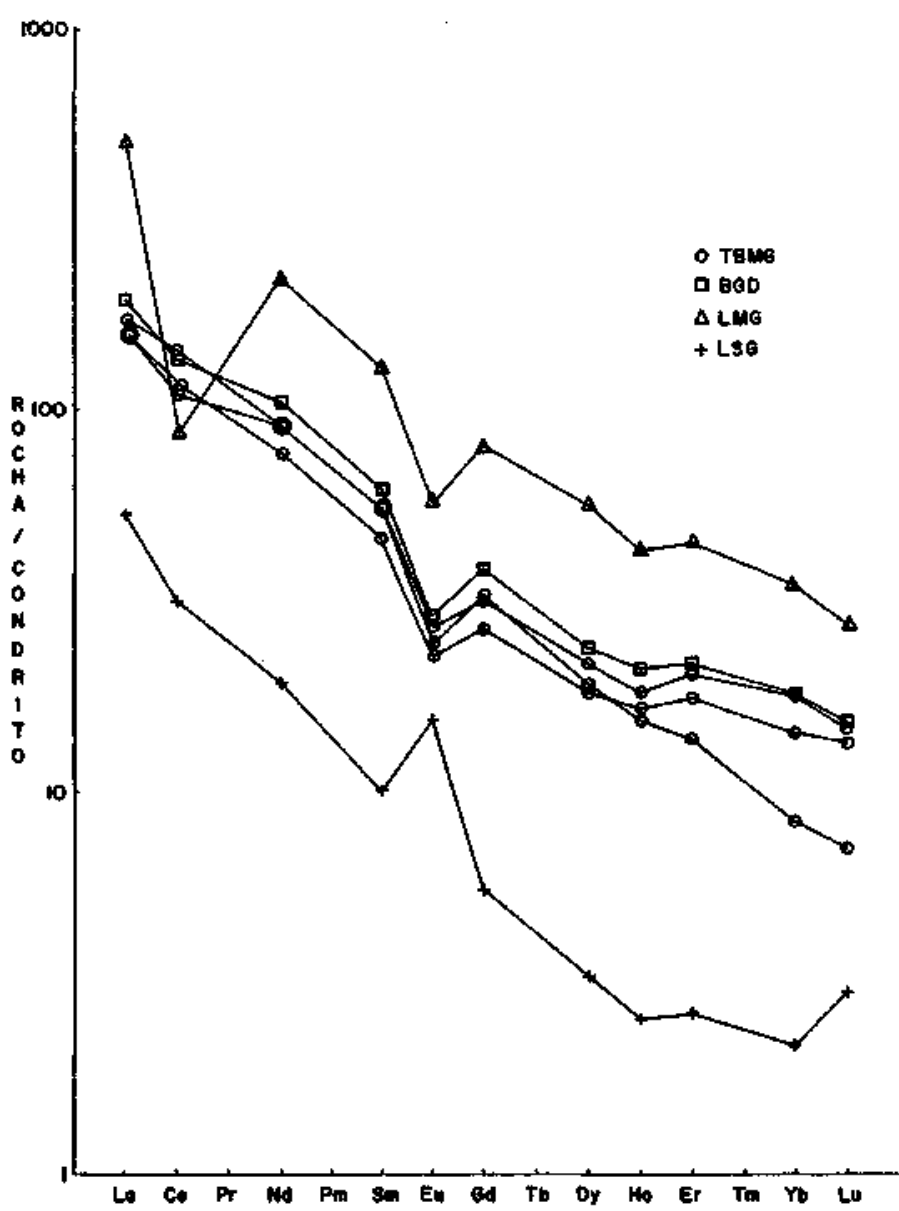

Figura 10 - Assinaturas de terras raras de amostras representativas do Granito Rio Uaupés

Figure 10 - Rare earth element patterns for the Rio Uaupés Granite

muito próximas daquela do Granito Rio Uaupés $(\mathrm{Rb} / \mathrm{Sr})$ e eles apresentam texturas rapakivi apenas localmente, não sendo descritos típicos viborgitos (Anderson \& Bender 1989). Eles são formados a partir de magmas cristalizados sob elevada fugacidade de oxigênio e são considerados pelos autores como pertencentes a série anorogênica com magnetita.

Concluindo, o Granito Rio Uaupés não apresenta características coincidentes com aquelas observadas nos granitos colisionais típicos do Fanerozóico. Ele diverge igualmente dos granitóides shoshoníticos e dos granitos rapakivíticos mais comuns. Assemelha-se, de modo notável, aos granitóides proterozóicos do tipo A do sudoeste dos Estados Unidos.

CARACTERIZAÇÃO E EVOLUÇÃO DO MAGMA GERADOR DO GRANITO RIO UAUPÉS Pelo exposto, é possível concluir que o Granito Rio Uaupés foi formado a partir de um magma subalcalino, cafêmico, com elevada razão $\mathrm{FeO}_{\mathrm{t}} /\left(\mathrm{FeO}_{\mathrm{t}}+\mathrm{MgO}\right)$. Esse magma foi, ao mesmo tempo, rico em $\mathrm{Ti}, \mathrm{K}, \mathrm{Ca}, \mathrm{Sr}$ e $\mathrm{Rb}$, e a dominância de granitos com teores moderados de $\mathrm{SiO}_{2}$ demonstra que o mesmo não era muito silicoso. Esses aspectos, aliados aos teores de anortita dos plagioclásios e altos conteúdos modais de máficos sobretudo titanita, opacos e apatita -, indicam que o magma foi gerado em temperaturas elevadas, seja por diferenciação de um magma primitivo, anatexia crustal ou hibridização. A hipótese, mencionada no estudo petrográfico (Dali'Agnol \& Macambira 1992), de que os núcleos cálcicos de plagioclásio, os minerais acessórios precoces e o anfibólio possam representar resíduos de fusão, implicaria temperaturas mais baixas para o líquido magmático; porém, ela parece menos provável. Admite-se, portanto, que o magma inicial continha poucas

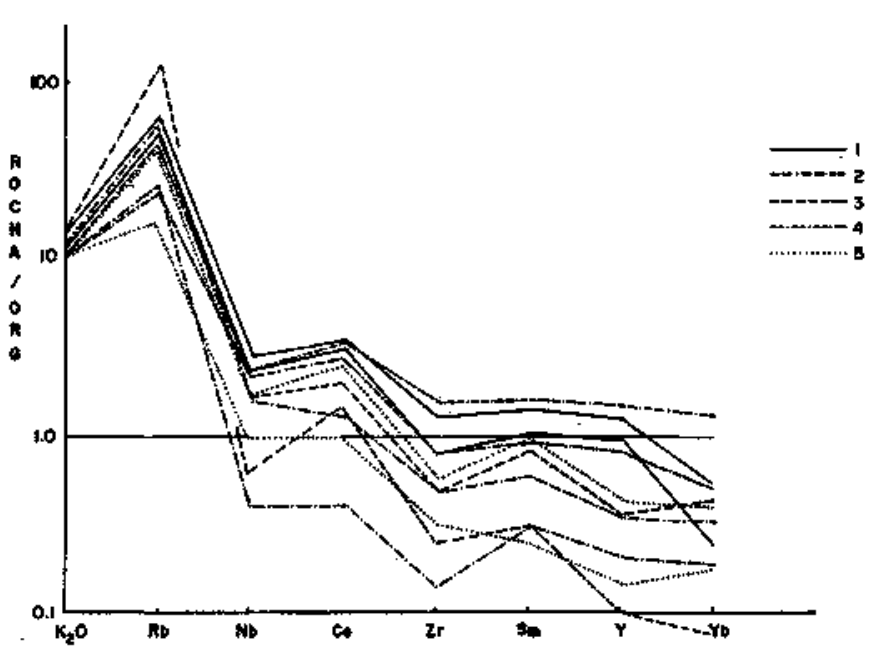

Figura $H$ - Análises do titanita-biotita monzogranito do Rio Uaupés normalizadas em relação ao granito de cadeia oceânica $(O R G)$, conforme proposto por Pearce et al. (1984). As diversas séries tomadas para comparação baseiam-se igualmente nesses autores. 1. Titanita-biotita monzogranito Rio Uaupés; 2. granitóides intraplacas de litosfera continental atenuada; 3. granitóides sin-colisionais; 4. granitóides pós-colisão; 5. granitóides de arco-vulcânico

Figure 11 - The titanite-biotitemonzogranite compositions (Rio Uaupés Granite) normal ized to the ocean ridge granite (ORG). Different series taken from Pearce et al. (1984) form comparison

fases residuais e estima-se temperatura de $950 \pm 50^{\circ} \mathrm{C}$ com base em estudos experimentais (Brown \& Fyfe 1970, Whitney 1975, Wyllie et al. 1976). Essa estimativa depende em grande parte do conteúdo de água do magma, que não é conhecido. A inexistência de transformações tardi a pós-magmáticas expressivas e escassez ou ausência de fases como muscovita, fluorita e turmalina, mesmo nas rochas mais evoluídas, sugerem baixos conteúdos de voláteis no magma e, em conseqüência, temperaturas mais elevadas para o início de sua cristalização. E assumido, portanto, que o magma era subsaturado em água e manteve-se assim durante a maior parte de sua cristalização. A saturação só foi atingida próximo à temperatura do solidus, situado em torno de $700^{\circ} \mathrm{C}$, uma vez que não há evidências de fases voláteis como $\mathrm{F}$ e B aptas a reduzir tal temperatura (Pichavant \& Manning 1984).

Há poucos elementos capazes de permitir uma dedução razoável das pressões em que se deu a evolução do magma. Porém, a própria natureza do mesmo indica como mais provável para a sua geração uma pressão elevada, compatível com aquelas da base de uma crosta continental ou na porção superior do manto. A disposição dos pontos representativos dos TBMG e BGD no diagrama Qz-Ab-Or (Fig. 6a) e a coincidência dos mesmos com as curvas cotéticas a 7 e 10 $\mathrm{kbar}$, poderia sugerir que o magma tenha sido originado a tais pressões, conforme argumentado por Anderson \& Bender (1989, p. 35). Porém, tais curvas foram obtidas experimentalmente sob condições de saturação em $\mathrm{H}_{2} \mathrm{O}$ (Winkler 1979), condições essas bem distintas das assumidas para o magma em discussão. Além disso, sendo os TBMG e BGD ricos em máficos e contendo plagioclásio andesínico, é pouco provável que os seus líquidos geradores correspondam a fusões cotéticas. Por outro lado, esse diagrama confirma a semelhança existente entre o Granito Rio Uaupés e o magmatismo granítico do tipo A dó sudoeste dos Estados Unidos. Pressões de 8,5 $\pm 1,5$ kbar, similares às assumidas por Anderson \& Bender (1989), embora não demonstradas, parecem igualmente adequadas para o Granito Rio Uaupés. 
A pressão vigente durante a colocação do magma e o final de sua cristalização é também difícil de precisar, mas, considerando a ausência na área de ocorrência do granito de seqüências metamórfícas supracrustais, vulcânicas e sedimentares, é possível pensar num nível relativamente profundo de erosão e numa colocação do corpo a pressões da ordem de 4,5 $\pm 0,5$ kbar (?).

A abundância de magnetita no Granito Rio Uaupés, traduzida nos seus valores elevados de suscetibilidade magnética, o caracteriza inequivocamente como granito da série com magnetita (Ishihara 1981). Esse fato e a presença marcante da associacão magnetita + titanita + quartzo, nos estágios mais avançados da cristalização, atestam, conforme Wones (1989), que o magma evoluiu em condições de fugacidade de oxigênio elevada, iguais ou superiores àquelas dos tampões NNO e HITMQ. Condições similaresforamobservadasemoutrosgranitos com magnetita da Amazônia (Dall'Agnol et d. 1990, Magalhães \&Dall'Agnol 1992).

Considerando os aspectos texturais, a ordem de cristalização estabelecida para o TBMG (Dall'Agnol \& Macambira 1992) e as hipóteses assumidas, a cristalização começaria com a separação de $\mathrm{Op}+\mathrm{Ap}+\mathrm{Zr}+\mathrm{Anf}+\mathrm{Pl}$ andesínico, ainda na base da crosta, a pressões elevadas. A ascensão do magma dariase com uma porcentagem líquido/cristais elevada, justificando a ausência de foliação no corpo granítico (Pitcher 1979, Castro 1987). Em níveis crustais mais elevados, começaria a cristalização do feldspato alcalino e do plagioclásio oligoclásico, seguindo-se aquelas de Qz, Tit e Bt, fases mais tardias. O anfibólio seria possivelmente desestabilizado devido à mudança de pressão e/ou evolução do líquido magmático, sendo substituído por biotita (o cálcio do anfibólio seria aproveitado pela titanita ou outras fases cálcicas). Nesse estágio, o plagioclásio andesínico já não seria mais estável, sendo envolvido por oligoclásio e, talvez, parcialmente corroído. Finalmente, após a colocação do magma, provavelmente no estágio subsolidus, desenvolveram-se as texturas intergranulares e as transformações de plagioclásio e biotita, pouco marcantes por causa da escassez de fases voláteis.

GÊNESE DO MAGMA Considerações sobre a origem do magma devem envolver dois aspectos fundamentais: o ambiente tectônico e o material fonte. Para o primeiro, é possível admitir: 1. ambiente anorogênico ou intraplacas (Anderson \& Bender 1989) ou, alternativamente, póstectônico (Vorma 1976), aceito de modo geral para o magmatismo rapakivítico ou do tipo $\mathrm{A} ; 2$. ambiente colisional, do tipo ensiálico, sem magmatismo de arco-deilhas ou do tipo andino associado, com pequena extensão e subsequente convergência, ou seja, subducção do tipo A, conforme proposto por Kroner (1983, apud Shackleton 1986, sua Tab. 1).

\footnotetext{
Hipótese de um magmatismo do Tipo A, anorogênico ou pós-tectônico Diversos autores discutiram hipóteses para explicar o magmatismo, aceito geralmente como bimodal, do Proterozóico Médio do Escudo Báltico e América do Norte (Bridgewater \& Windley 1973, Barker et al 1975, Vorma 1976, Emslie 1978, Anderson \& Cullers 1978, Anderson 1983, Nurmi \& Haapala 1986, Anderson \& Bender 1989, Windley 1989, Haapala \& Ramo 1990). Quase todos eles assumem modelos envolvendo fusão parcial de uma crosta continental, causada por magmas básicos intrudidos na base da crosta e associados a plumas do manto ou a hot-spots. Vorma (1976, p.85) propõe um modelo distinto, admitindo que a geração dos magmas se faria igualmente na base da crosta continental, porém durante o clímax de uma orogenia e sem envolver magmas básicos. Segundo ele, a colocação do magma, assim gerado, daria-se durante o estágio pós-tectônico e nã̃o anorogênico. As rochas-fonte admitidas nos dois casos seriam metaígneas (tonalitos ou afins) com variáveis contribuições sedimentares, e, por vezes, granulitos.
}

O Granito Rio Uaupés difere geoquimicamente dos típicos granitos epizonais rapakivíticos e assemelha-se notavelmente aos granitos do tipo A do sudoeste dos Estados Unidos (variedades menos ricas em silica). Este trabalho assumiu anteriormente que a colocação do primeiro deu-se em profundidades consideráveis, aproximando-se nesse sentido das suítes monzoníticas (cf. Emslie 1978). Sua rocha-fonte teria necessariamente que ser mais pobre em silica que tonalitos, a menos que se assuma fusão total, que não explicaria $o$ enriquecimento no líquido em determinados elementos, como $\mathrm{Nb}, \mathrm{Y}, \mathrm{TRL}, \mathrm{Zr}$ etc. Logo, poderia-se pensar em associações de gabros quartzosos, jotunitos e mangeritos ou de dioritos e quartzo dioritos relativamente ricos em potássio ou em granuiitos de composições similares, embora os yltimos sejam menos prováveis por serem menos aptos a concentrar, os elementos incompatíveis. Essa fonte crustal deveria ser submetida necessariamente a um grau de fusão importante, de modo a explicar o enriquecimento em cálcio e em fases máficas no Granito Rio Uaupés, e o resíduo seria formado essencialmente por hornblenda ( \pm piroxênios) e plagioclásio, justificando o comportamento dos elementos terras raras nos TBMG. Tal associação seria condizente com uma fonte a base de gnaisses gabróicos quartzosos, jotunitos e mangeritos ou de dioritos e quartzo-dioritos. Outra alternativa seria uma fonte granulítica, com piroxênios e, talvez, hornblenda e granada, constituindo, ao lado do plagioclásio, o resíduo.

A maior dificuldade para aceitação dessa hipótese reside nas evidências de atuação de um evento tectônico na Província Rio Negro entre 1.700 e $1.500 \mathrm{Ma}$, o qual, aparentemente, teria sido capaz de gerar rochas similares ao Granito Rio Uaupés, tanto sintectônicas (atuais gnaisses), quanto póstectônicas (o próprio granito), conforme evidenciado pelos dados geocronológicos (Cf. Dall'Agnol et al. 1987, Dall'Ágnol \& Macambira 1992). A sua adoção implicaria, portanto, deixar de lado as hipóteses de arco magmático (Tassinari 1981, Teixeira et al. 1989) e de colisão continental (Dall'Agnol et al. 1987) colocadas anteriormente, bem como rever a interpretação dos dados geocronológicos e o ambiente tectônico.

Hipótese de um magmatismo associado à Zona de Colisão As diferenças geoquímicas marcantes entre as rochas estudadas e os granitóides representativos de magmatismo de zonas de colisão do Fanerozóico deixam pouco espaço para admitir que o Granito Rio Uaupés possa estar associado a zonas de subducção ou a um magmatismo colisional do tipo S, como o do Alto-Himalaia. Uma alternativa teórica seria adotar o modelo de England \& Thompson (1986) e admitir que um acentuado espessamento crustal durante a colisão permitiria que fossem atingidas temperaturas excepcionalmente elevadas na base da crosta, de modo a fundir as rochas aí existentes e gerar magmas. Dependendo do fluxo térmico, velocidade de erosão e outras variáveis, em condições favoráveis, o espessamento crustal poderia conduzir a ampla fusão crustal. Nessas condições, rochas tonalíticas ou gnaisses equivalentes, bem como anfibolitos poderiam ser fundidas, mesmo em condições de subsaturação, gerando magmas cálcio-alcalinos ou outros.

Sendo admitidos rochas-fonte e grau de fusão similares aos discutidos na hipótese anterior, esse modelo poderia explicar a geração do Granito Rio Uaupés e tipos similares, e dos gnaisses mais antigos, pois a formação dos magmas e a sua colocação poderia dar-se durante os diferentes estágios da colisão, ou seja, desde a fase sintectônica até a pós-tectônica.

Hipótese de geração do magma por hibridização ou mistura de magmas Para explicar a evolução da associação presente no Maciço de Ploumanac'h, Barrière (1977) propôs processo de contaminação em condições mantélicas ou crustais, ou ambas, envolvendo magma álcali-basáltico do manto, apenas ligeiramente subsaturado, de modo a enriquecêlo em K e Si. Esse magma contaminado geraria a série 
subalcalina potássica, saturada em silica de Ploumanac'h, que abrange de gabros a granites. Sua origem seria dominantemente mantélica. Fourcade (1981) sugeriu que os granitos subalcalinos potássicos poderiam ser gerados pela mistura de magmas do manto com magmas crustais, havendo predominância dos últimos. Nardi (1986) assume derivação mantélica para os magmas das séries shoshoníticas. Dall'Agnol et al. (1987, p.395) consideraram a hipótese de mistura entre magmas mantélicos e materiais crustais para explicar a gênese dos granitos tipo Uaupés da PRN.

As diferenças geoquímicas entre o Granito Rio Uaupés e os granitóides shoshoníticos, discutidas anteriormente, e, sobretudo, as suas baixas razões $\mathrm{MgO} /\left(\mathrm{MgO}+\mathrm{FeO}_{\mathrm{t}}\right)$ tornam difícil aceitar origem do primeiro a partir de diferenciação de magma basáltico mantélico, mesmo envolvendo certo grau de contaminação crustal. A hipótese assumida por Barrière (1977) para o maciço Ploumanac'h apresenta, no caso em discussão, essas mesmas limitações. A única alternativa plausível seriaadmitir interação entre magma básico mantélico e crosta, resultando dominância dos componentes crustais no magma gerador do Granito Rio Uaupés. Porém, mesmo nessas condições, não é seguro que pudessem ser obtidos magmas capazes de gerar rochas com as características geoquímicas do Granito Rio Uaupés.

DISCUSSÃO E CONCLUSÕES Arazãoinicial ${ }^{87} \mathrm{Sr} /$ ${ }^{86} \mathrm{Sr}=0,706$ obtida para o Granito Rio Uaupés (Dall'Agnol \& Macambira 1992) sugere seja uma fonte crustal, seja um magma mantélico com contribuição crustal importante. É possível portanto, em princípio, descartar a hipótese de derivação do magma exclusivamente a partir de fonte mantélica, como, por exemplo, por meio de diferenciação de magma basáltico. A hipótese de geração em zona de subducção, envolvendo arco-de-ilhas ou margem continental do tipo andino, é difícil de conciliar com a ausência de comprovação de magmatismo cálcio-alcalino na PRN. Finalmente, o granito estudado difere geoquimicamente das séries cálcioalcalinas colisionais e também dos granitos peraluminosos derivados de fontes metassedimentares crustais.

O modelo de magma mantélico com contribuição crustal não pode ser inteiramente descartado, mas não parece o mais coerente com os dados disponíveis. Resta, como alternativa, a geração do magma em condições crustais, a partir da fusão de materiais da base da crosta, a pressões elevadas. Tais condições podem ser verificadas, tanto no modelo adotado para explicar a gênese dos granitos do tipo A e rapakivíticos, quanto no modelo de fusão crustal de England \& Thompson (1986) para as zonas de colisão. A opção entre os dois modelos depende essencialmente do ambiente tectônico assumido para a PRN. Adotar o primeiro, implicaria afastar a hipótese de colisão, pois ele supõe condições distensionais.
É óbvio que, face às limitações de escala do mapeamento geológico da PRN e de dados estruturais, não é possível ser conclusivo sobre sua evolução tectônica. Porém, a notável concentração de dados geocronológicos no período entre 1.800 e $1.500 \mathrm{Ma}$ (Tassinari 1981,Priem et al. 1982, Gaudette \& Olszewski 1985, Dall'Agnol \& Macambira 1992) sugere que ela foi afetada por um evento tectônico marcante nesse período, o qual envolve metamorfismo e intenso magmatismo. A ocorrência freqüente, na PRN, de gnaisses petrográfica e geoquimicamente similares ao Granito Rio Uaupés, e a presença na mesma da Suíte Rio Içana (Lima \& Pires 1985), formada por típicos granitos peraluminosos do tipo $\mathrm{S}$, não favorecem a hipótese de que os granitóides do Proterozóico Médio, incluindo o Granito Rio Uaupés, tenham sido formados em ambiente anorogênico. Em razão disso, é preferível, no momento, admitir que a gênese do Granito Rio Uaupés estejarelacionadaaumacolisão segundo o modelode England \& Thompson (1986), ou à formação de um cinturão móvel com intenso magmatismo associado (Kroner 1977). No entanto, caso essas duas hipóteses não se confirmem em estudos futuros, a alternativa de geração do magma tipo Granito Rio Uaupés em condições distensionais, possivelmente intraplaca, deveria ser reavaliada, buscando uma explicação para a origem dos gnaisses afins do Granito Rio Uaupés e da Suíte Rio Içana. Finalmente, sendo aceita a hipótese de colisão continental, aausência de granitóides similares ao magmatismo Uaupés em zonas de colisão fanerozóicas implicaria admitir certas peculiaridades geoquímicas na crosta proterozóica onde o mesmo foi gerado (cf. Anderson \& Bender 1989).

Agradecimentos Ficam registrados nossos agradecimentos a: M.J.B. Macambira, J.M. Lafon, L.V.S. Nardi e M.1.C. Lima, por discussões e sugestões recebidas; a F. Debon, pela orientação na utilização e interpretação de determinados diagramas e por críticas na fase de elaboração desse trabalho; a G. Dreux, pelo tratamento de dados; a W.K. Schuckmann, N.V. Siqueira e A. Vaquera, pelo apoio nas análises químicas; aos colegas do projeto IGCP-204, pelas discussões e estímulo à realização desse trabalho; a C.M.G. Silva, pela elaboração de diagramas; aos desenhistas e técnicos de laboratórios analíticos do CG-UFPA, pela sua colaboração; a D.N.P. Almeida, pela datilografia do texto. Essa pesquisa foi apoiada financeiramente por PADCT-FINEP (projeto 4.3.87.0911.00) e, em sua fase inicial, pelo projeto IGCP-204 (IUGS-UNESCO). Ela foi iniciada e concluída no CG-UFPA, tendo sido a etapa intermediária efetuada no Centre de Recherches Pétrographiques et Géochimiques (CRPG-CNRS, Vandoeuvre, França), quando o autor desenvolvia um programa de pós-doutorado, usufruindo de bolsa do PADCT-CAPES. Somos gratos às instituições mencionadas pelo apoio recebido.

\section{REFERÊNCIAS BIBLIOGRÁFICAS}

ALBUQUERQUE,C.A.R. 1978. Rare earth elements in "Younger" granites, northern Portugal. Lithos, 11:219-229.

ANDERSON, J.L 1983. Proterozoic anorogenic granite plutonism of North America. In: MEDAR1S, L.G., Jr.; BYERS, C.W.; MICKELSON, D.M; SHANKS W.C., eds. Proterozoic Geology: Selected papers from International Proterozoic Symposium. Madison, Geol. Soc. Am., Mem. 161:133-154.

ANDERSON, J.L. \& BENDER, E.E. 1989. Nature and origin of Proterozoic A-type granitic magmatism in the southwestern United States of America. 1/7/705,23:19-52

ANDERSON, J.L.\& CULLERS, R.L. 1978. Geochemistry and evolution of the Wolf River Batholith, a Late Precambrian rapakivi massif in North Wisconsin, USA. Prec Res, 7:287-324.

BARKER,F. 1979. Trondhjemite: Definition, environment and hypothesis of origin. In: BARKER, F. ed. Trondhjemites, dacites, and related rocks. Amsterdam, Elsevier. p. 1-12. (Development in Petrology 6).

BARKER, F-WONES, D.R.; SHARP, W.N.; DESBOROUGH, G.A. 1975. The Pikes Peak Batholith, Colorado Front Range, and amodel forthe origin of the gabbro-anorthosite-syenite-potassic granite suite. Prec.Res., 2:97160.
BARRIERE, M. 1977. Le complexede Ploumanac'h (Massif Armoricain). Essai sur la mise en place et l' evolution pétrologique d 'une association plutonique subalcaline tardi-orogénique. Brest. 291 p. (These Doct. d'Etat. Univ. Brest)

BRIDGWATER,D.\&WINDLEY,B.F. 1973. Anorthosites, post-orogenic granites, acid volcanicrocks and crustal development in the North Atlantic Shield during the M id-Proterozoic. In: SYMP. GRANITES, GNEISSES AND RELATED ROCKS. Geol. Soc. S. Aft. p. 307-317. (Spec. Publ. 3).

BROWN, G.C.\&FYFE,W.S. 1970. The production of granitic melts during ultrametamorphism. Contrib. Mineral. Petrol.. 28:310-318.

CASTRO, A. 1987. On granitoid emplacement and related structures: a review. Geol. Rund.l6(): $|O|-\mid 24$

CULLERS,R.L.\&GRAF,J.L. 1984. Rare earth elements in igneous rocks of the continental crust: intermediate and silicic rocks-ore petrogenesis. In HENDERSON, P. ed. Rare Earth Element Geochemistry. New York, Elsevier. p. 275-316.

DALL'AGNOL, R ; BETTENCOURT, J S ; JORGE-JOÃO X.S ; MEDEIROS, H.:COSTI,H.T; MACAMBIRA, M.J.B. 1987. Granitogenesis in the Northern Brazilian region: a review. Rev.Bras.Geoc., 17(4):382-403. 
DALL'AGNOL, R. \&MACAMBIRA,M.J.B. 1992. Titanita-biotita granitos do baixo Rio Uaupés, Província Rio Negro, Amazonas. Parte l: geologia, petrografíae geocronologia. Rev.Bras.Geoc., 22(1): 3-13

DALL'AGNOL, R.; PICHA VANT, M.; CHAMPENOIS, M. 1990. Minerais opacos e evolução magmática: o exemplo dos granitos anorogênicos da AmazôniaOriental. In: CONGR.BRAS.GEOL,36. Natal, 1990. Resumos ...Natal,SBG,p.166.

DALL'AGNOL, R.; SAUCK, W.A.; GONÇALEZ, M.G.B. 1988. Suscetibilidademagnéticaemgranitóides da Amazônia: um estudo preliminar. In: CONGR.BRAS.GEOL., 35. Belém, 1988. Anais... Belém, SBG.v. 3, p. 1164-1173.

DEBON, F. \& LE FORT, P. 1988. A cationic classification of common plutonic rocks and their magmatic associations: principles, method, appl ications. Bull.Mineral., in 4 493-SlO

DEBON, F.;LE FORT, P.; SHEPPARD,S.M.F.; SONET, J. 1986. The four plutonic belts of the Transhimalaya-Himalaya:achemical,mineralogical isotopic, and chronological synthesis along a Tibet-Nepal section. $J$. Petrol.,27(l):219-25Q.

EMSLIE,R.F. 1978. Anorthosite massifs, rapakivi granites, and Late Proterozoic rifting of North America. Free. Res, 7:61 -98.

ENGLAND, P.C. \& THOMPSON, A 1986. Some thermal and tectonic models for crustal melting in continental collision zones. In: COWARD, M.P. \& RIES, A.C. eds. Collision Tectoniques. London, Blackwell Sc Publ. p. 83-94. (Geol.Soc.Special Publ. 19).

FOURCADE,S. 1981. GéochimimiedesGranitoides. Paris. 198 p. (These de Doctoral d'Etat, Université Paris VII).

FOURCADE,S.\&ALLEGRE,J.C. 1981. Trace elements behavior in granite genesis: acase study the calc-alkaline plutonic association from the Quérigut Complex (Pyrenees, France). Contrib. Mineral. Petrol., 76:177-195.

GAUDETTE, H.E.; HURLEY P.M.; FAIRBAIRN, H.W.; ESPEJO, A.; DAHLBERG,E.H. 1978. Older Guiana basement south of the Imataca Complex in Venezuela and in Suriname. Geol. Soc. America. Bull., 89:1290-1294.

GAUDETTE, H.E. \& OLSZEWSKI JR., W.J. 1985. Geochronology of the basement rocks, Amazonas Territory, Venezuela, and the tectonicevolution ofthe Western GuianaShield. Geol. Mijnboitw, 64:131 -143.

HAAPALA,I.\&RAMO,O.T. 1990. Petrogenesis of the Proterozoic rapakivi granites of Finland. In: STEIN, H.J. \& HANNAH, eds. Ore bearing granite systems; Petrogenesis and mineralizing processes. Geol. Soc. America, p. 275-286. (Special Paper 246)

HARRIS, N.B.W.; PEARCE, J.A.; TINDLE, A.G. 1986. Geochemical characteristics of collision-zone magmatism. In: COWARD, M.P. \& RIES, A.C. eds. Collision Tectonics. London, Blackwell Sc. Publ. p.67-81 (Geol.Soc.Special Publ. 19)

HASKIN, L.A.; HASKIN, M.A.; FREY, F.A.; WILDEMAN, T.R. 1968 Relative and absolute terrestrial abundances ofthe rare earths. In: L.H. AHRENS ed. Origin and Distribution of the Elements. London, Pergamon Press, p. 889-912.

HENDERSON, P 1984 General geochemical properties and abundances of the rare earth elements. In: HENDERSON, P ed. Rare Earth Element Geochemistry. Amsterdam, Elsevier. p. 1 -32.

ISHIHARA, S. 1981. The granitoid series and mineralization. Econ. Geol. 75:458-484

KRONER, A. 1977. The Precambriangeotectonic evolution of Africa: plate accretion versus plate destruction. Prec. Res. 4:163-213.

KROONENBERG,S.B. 1981. El borde occidentaldel'escudo de Guyana en Colombia. In: SIMP.AMAZ.. 1. Puerto Ayacucho, 1981.42 p. (Mimeogr.)

LA ROCHE, H.; LETERRIER, J.; GRANDCLAUDE, P.; MARCHAL, M. 1980. A classification ofvolcanicandplutonic rocks using RIR2-diagram and majorelement analyses-Its relationships with current nomenclature. Chem.Geol., 29:183-210.

LEMOS, V.P. 1990. Evolução Mineralógica e Geoquímica de Lateritos sobre Rochas do Complexo de Maicuru-Pará. Belém. 256 p. (Tese de Doutoramento, Centro de Geocièncias/UFPA).

LETERRIER, J. 1972. Etude pétrographique et géochimique du massif granitique de Quérigut (Ariège). Mém. Sei. de Ia Terre, 23:292 p.

LIMA, M.I.C. \& PIRES, J.L. 1985. Geologia da região do Alto Rio Negro AM.In:SIMP.GEOL.AMAZ.,2.Belém,1985./1«a/í...Belém,SBG.v. 1, p. $140-154$

MAGALHÃES, M.S. \& DALL'AGNOL, R. 1992. Estudo de minerais opacos e suscetibilidade magnética nos granitos Musa e Jamon (região de Rio Maria - SE do Pará) e suas impl icações petrológicas. Rev. Bras. Geoc., (No prelo).

MANIAR, P.D. \& PICCOLI, P.M. 1989. Tectonic discrimination of granitoids. Geol. Soc. America Bull., 101:635-643.
MARRE, J. 1973. Lê Complexe Eruptif de Quérigut. Pétrologie, Structorologie, Cinématique de Mise en Place. Toulouse. 536p. (These Doctoral, d'Etat, Univ. Paul Sabatier).

MENDOZA, V. 1975. Estúdios geoquímicos del notectonizado granito Rapakivi EI Parguaza, Noroeste Guyana Venezolana. In: CONF. GEOL. INTERGUIANAS, IO. Belém, 1975. Anais... Belém, DNPM. p. 628656.

MORRISON, G. W. 1980. Characteristics and tectonic setting of the shoshonite rock association. Lithos, 13:97-108.

NARDI,L.V.S. 1986. As rochasgranitóidesdasérieshoshonítica./tev. Bras. GE?oc.,16(1):3-10.

NARDI,L.V.S.\&LIMA,E.F. 1985. A associação shoshonítica de Lavras do Sul, RS. Rev. Bras. Geoc., 15(2): 139-146.

NURMI,P.A.\&HAAPALA,I. 1986. The Proterozoic granitoids of Finland: Granite types metallogeny and relation to crustal evolution. Bull. Geol. Soc. Finland, 58(1):203-233.

PAGEL,M. 1982. The mineralogy and geochemistry of uranium, thorium, and rare-earth elements in two radioactive granites ofthe Vosges, France. Mineral. Mag., 46(339): 149-161.

PAGEL,M.\& LETERRIER, J. 1980. The subalkalinepotassic magmatism ofthe Ballons massif (Southern Vosges, France): shoshonitic affinity. Lithos, 13:1-10

PEARCE, P.O.; HARRIS, N.B.W.; TINDLE, A.G. 1984. Trace element discrimination diagrams for the tectonic interpretation of granitic rocks. J. >ee/ro/.,25(4):956-983.

PICHAVANT, M. \& MANNING, D. 1984. Petrogenesis of tourmaline granites and topaz granites: the contribution of experimental data. Phys. Earth Planet. Int., 35:31-50.

PITCHER, W.S. 1979. The nature, ascent and emplacement of granitic magmas. J. Geol. Soc. London, 136:627-662.

PRIEM, H.N.A.; ANDRIESSEN, P.A.M.; BOELRIJK, N.A.I.; BOORDER, H.; HEBEDA, E.H.; HUGUETT, A.; VERDURMEN, E.A.T.H.; VERS CHURE,R.H. 1982. Geochronology ofthe Precambrian in the Amazonas region of southeastern Colombia( Western GuianaShield). Geol. Mijnbouw, 61:229-242.

SHACKLETON, R.M. 1986. Precambrian collision tectonics in Africa. In: COWARD, M.P. \& RIES, A.C. eds. Collision Tectoniques. London, Blackwell Sc. Publ. p. 329-349. (Geol. Soc. Special Publ. 19).

TASSINARI, C.C.G. 1981. Evolução Geotectônica da Província Rio NegroJuruena na Região Amazônica. São Paulo, 99p. (Dissertação de Mestrado, $\mathrm{IG} / \mathrm{USP})$.

TEIXEIRA, W.;TASSINARI, C.C.G.; CORDANI, U.G.; KAWASHITA, K. 1989. A review of the geochronology ofthe Amazonian Craton: tectonic implications. Prec. Res., 42:213-227.

VAN SCHMUSS, W.R.; BICKFORD, M.E.;ZIETZ, I. 1987. Early and Middle Proterozoic provinces in the Central United States. In: KRONER, A. ed. Proterozoic Lithospheric Evolution. Am. Geoph. Union and Geol. Soc. America, p. 43-68. (Geodinamic Series, v. 17).

VORM A, A. 1976. On the petrochemistry of rapakivi granites with special reference to the LaitilaMassif, southwestern Finland. Geol. Surv. Finland Bull., 285:98 p.

WAKITA, H.; REY, P.; SCHMITT, R.A. 1971. Abundances ofthe 14 rare earth elements and 12 other rare elements in Apollo 12 samples: five igneous and one breccia rocks and four soils. In: Proc. 2nd Lunar Sci. Conf. Geoch. Cosmoch. Acta, (Suppl. 2). 2:1319.

WHITE,A.J.R.\&CHAPPELL,B.W. 1977. Ultrametamorphism and granitoid genesis. Tectonophysics, $43: 7-22$.

WHITNEY, J. A. 1975. The effects of pressure, temperature and $\mathrm{XH}_{2} \mathrm{O}$ on phase assemblage in four synthetic rock compositions. J. Geol., 83( I): 1 31 .

WINDLEY,B.F. 1989. AnorogenicmagmatismandtheGrenvillianOrogeny. Can. J. Earth Sci., 26:479-489.

WINKLER, H.G.F. 1979. Petrogenesis of Metamorphic Rocks. 5 ed. New York, Springer-Verlag. 348 p

WONES, D.R. 1989. Significance ofthe assemblage titan ite+magnetite+ quartz in granitic rocks. Am. Mineral., 74:744-749.

WYLLIE.P.J.; HUANG, W.L.; STERN, C.R.;MAALOE,S. 1976. Granitic magmas: possible and impossible sources, water contents, and crystallization sequences. Can. J. EarthSci., 13(8):1007-1019.

MANUSCRITO A705

Recebido em 24 de julho de 1991 Revisão do autor em 20 de janeiro de 1992 Revisão aceita em 20 de janeiro de 1992 